\title{
In-situ spectroscopy and shortwave radiometry reveals spatial and temporal variation in the crown-level radiative performance of urban trees
}

\section{Article}

Accepted Version

Creative Commons: Attribution-Noncommercial-No Derivative Works 4.0

Deng, J. ORCID: https://orcid.org/0000-0001-6896-8622, Pickles, B. ORCID: https://orcid.org/0000-0002-9809-6455 and Shao, L. (2021) In-situ spectroscopy and shortwave radiometry reveals spatial and temporal variation in the crownlevel radiative performance of urban trees. Remote Sensing of Environment, 253. 112231. ISSN 0034-4257 doi: https://doi.org/10.1016/j.rse.2020.112231 Available at https://centaur.reading.ac.uk/94651/

It is advisable to refer to the publisher's version if you intend to cite from the work. See Guidance on citing.

To link to this article DOI: http://dx.doi.org/10.1016/j.rse.2020.112231

Publisher: Elsevier

All outputs in CentAUR are protected by Intellectual Property Rights law, including copyright law. Copyright and IPR is retained by the creators or other copyright holders. Terms and conditions for use of this material are defined in the End User Agreement. 


\section{www.reading.ac.uk/centaur}

\section{CentAUR}

Central Archive at the University of Reading

Reading's research outputs online 
Manuscript for Remote Sensing of Environment

In-situ spectroscopy and shortwave radiometry reveals spatial and temporal variation in the crown-level radiative performance of urban trees

Jie Deng a, ${ }^{\text {a, }}$, Brian J. Pickles ${ }^{b}$, Li Shao ${ }^{a}$

${ }^{a}$ School of The Built Environment, University of Reading, Whiteknights, Reading, Berkshire, RG6 6DF, UK

b School of Biological Sciences, University of Reading, Harborne Building, Whiteknights, Reading RG6 6AS, UK.

* Corresponding author:

E-mail address: j.deng@ reading.ac.uk; deng-jie2@163.com (J. Deng) 


\section{In-situ spectroscopy and shortwave radiometry reveals spatial and} temporal variation in the crown-level radiative performance of urban

\section{trees}

\section{Abstract}

In conventional microclimate environment modelling, and the development of tree planning strategies for urban heat mitigation, tree crown surface albedo for any given species is assumed to be a constant. However, our recent research into urban tree radiative performance at the crown level implied that tree crown surface albedo changes over time. Based on the in-situ spectroscopy protocols established previously to measure tree crown transflectance, variation in the characteristics of tree crown surface albedo was explored combining spectroscopy and solar shortwave radiometry. Three commonly planted native UK tree species, Carpinus betulus, Acer campestre, and Taxus baccata, were sampled. Spatial distribution profiles of tree crown transflectance measured at fixed solar altitudes were normalised by in-situ spectroradiometry. Tree crown transflectance in the near infrared (NIR) region was found to be proportionally linked to tree crown surface albedo. Within each species, mean tree crown transflectance in the NIR region of $800-900 \mathrm{~nm}$ was approximately 2.5 times tree crown surface albedo. It was further found that infrared radiation (700-2500 nm) accounted for more than $90 \%$ of the total transflected shortwave radiation from tree crowns. The results demonstrate that tree crown surface albedo linearly increases with momentary solar altitude and the maximum tree crown surface albedo corresponds to 
maximum solar altitude at solar noon on sunny days in summer. Tree crown surface

24 albedo across species tends to be strongly dependent on leaf size if considering visibly dense crown foliage. Our findings provide important insights into tree radiative shading effects resulting from temporal variation in tree crown surface albedo, with consequences for urban microclimate modelling and the development of urban heat mitigation strategies.

Keywords: urban trees; radiative performance; in-situ spectroscopy; infrared radiation; shortwave radiometry; transflectance; tree crown surface albedo; urban microclimate 


\begin{tabular}{|c|c|}
\hline \multicolumn{2}{|l|}{ Nomenclature } \\
\hline $\operatorname{IRR}$ & solar irradiance, $\mathrm{W}$ \\
\hline$I R R_{\text {ref }}$ & solar spectral irradiance on a vertical reference plane, $\mathrm{W} /\left(\mathrm{m}^{2} \cdot \mathrm{nm}\right)$ \\
\hline$I R R_{S W, \text { incoming }}$ & incoming shortwave radiation or total solar irradiance, $\mathrm{W} / \mathrm{m}^{2}$ \\
\hline$I R R_{S W, \text { outgoing }}$ & outgoing shortwave radiation from tree crown, W/m² \\
\hline$I R R_{V A}$ & $\begin{array}{l}\text { solar spectral irradiance on the surface at a tilted angle of the viewing } \\
\text { angle }(V A), \mathrm{W} /\left(\mathrm{m}^{2} \cdot \mathrm{nm}\right)\end{array}$ \\
\hline$S F_{\tau R, 800-900}$ & $\begin{array}{l}\text { scale factor of mean transflectance in } 800-900 \mathrm{~nm} \text { range to tree } \\
\text { crown surface albedo, - }\end{array}$ \\
\hline$V A$ & $\begin{array}{l}\text { viewing angle of the spectrometer fiber-optic tip relative to } \\
\text { horizontal plane, }{ }^{\circ}\end{array}$ \\
\hline \multicolumn{2}{|l|}{ Greek symbols } \\
\hline$\alpha$ & solar altitude, ${ }^{\circ}$ \\
\hline$\lambda$ & wavelength, nm \\
\hline$\rho_{\text {albedo }}$ & tree crown surface albedo, - \\
\hline$\tau R$ & transflectance of tree crown contour, - \\
\hline$\tau R_{\text {mean }}$ & mean transflectance in a wavelength interval, - \\
\hline$\tau R_{\text {mean }, 800-900}$ & mean transflectance in the near infrared region of $800-900 \mathrm{~nm},-$ \\
\hline$\tau R(\lambda)$ & spectral transflectance at wavelength $\lambda \mathrm{nm},-$ \\
\hline$\tau R_{\text {meas }}(\lambda)$ & $\begin{array}{l}\text { measured spectral transflectance at } \lambda \mathrm{nm} \text { wavelength with a vertical } \\
\text { reference spectrum, - }\end{array}$ \\
\hline$\tau R_{\text {norm }}(\lambda)$ & $\begin{array}{l}\text { normalized spectral transflectance at } \lambda \mathrm{nm} \text { wavelength by } \\
\text { converting the reference irradiance spectrum in a vertical plane to } \\
\text { that in the direction of the viewing angle upwards, - }\end{array}$ \\
\hline \multicolumn{2}{|l|}{ Abbreviations } \\
\hline$I R$ & infrared \\
\hline$L A I$ & leaf area index \\
\hline NIR & near infrared \\
\hline$U H I$ & urban heat island \\
\hline$U V$ & ultraviolet \\
\hline VIS & visible \\
\hline
\end{tabular}




\section{Introduction}

Urban trees play an important role in urban biodiversity, sustainability and climate resilience (Konijnendijk et al., 2005). They can benefit human beings by mitigating heat waves, improving thermal comfort for pedestrians, absorbing carbon dioxide and producing oxygen via photosynthesis, enhancing urban drainage systems and soils, reducing air and noise pollution, providing visual and aesthetic value, and in many other ways (Konijnendijk et al., 2005; Roy et al., 2012). Heat waves have frequently hit many cities globally in the hot summers of the past two decades (Garcia-Herrera et al., 2010; IPCC, 2014; Christidis et al., 2015), leading to high mortality of city dwellers in different countries and regions (Gasparrini and Armstrong, 2011; Guo et al., 2017). In the context of mitigating heat waves and alleviating the effects of global warming, urban trees help to regulate the outdoor thermal environment through evaporative cooling and radiative shading effects (Armson et al., 2013; Wang et al., 2016; Kong et al., 2017; Wu and Chen, 2017; Wang et al., 2018; Tan et al., 2020).

Research on the benefits of trees for urban heat mitigation has generally focused on the effect of cooling through transpiration, in conjunction with tree physiological conditions, and it has widely been confirmed that urban trees help to mitigate urban heat stress and reduce outdoor temperature in different scenarios and climates (Bowler et al., 2010; Gillner et al., 2015; Lee et al., 2016; Kong et al., 2017; Yang et al., 2017; Zhou et al., 2017; Zhao et al., 2018; Taleghani, 2018; Aminipouri et al., 2019; Wang et 
al., 2019). Urban trees also have the potential to mitigate Urban Heat Island (UHI) effects (Tan et al., 2016; Jamei et al., 2016; Rahman et al., 2020b). Tree surface temperatures are commonly found to be close to ambient air temperature (within approximately $-2-5^{\circ} \mathrm{C}$ ) (Leuzinger et al., 2010; Irmak et al., 2018; Rahman et al., 2020a) in contrast with built surfaces, which tend to be significantly warmer. For example, surface temperatures of sealed ground in an open space are usually 10 to $20^{\circ} \mathrm{C}$ warmer than those of trees and green spaces in hot summers (de Abreu-Harbich et al., 2015; Gillner et al., 2015; Speak et al., 2020). It has also been observed that the mean radiant temperature of open fields can be reduced by up to $11-30{ }^{\circ} \mathrm{C}$ by trees (Gillner et al., 2015; Tan et al., 2017; Zheng et al., 2018; Park et al., 2019). Importantly for urban planning, the tree cooling effect can help to reduce building thermal energy use (Liu and Harris, 2008; Kong et al., 2016; Wang et al., 2016; Hsieh et al., 2018; Tang and Zheng, 2019; Moss et al., 2019), and hence may help to mitigate against increased energy consumption resulting from wider and longer use of air conditioning units. It is widely reported that leaf area index (LAI) is the main driving factor of tree cooling effects (Armson et al., 2013; Rahman et al., 2015; Morakinyo et al., 2018; Zhang et al., 2018), although it should be noted that other, less easily measured, functional traits are rarely considered. In general, tall trees with a large LAI and a wide canopy diameter are suggested to improve the outdoor thermal environment (Kong et al., 2017; Zhang et al., 2018). 
In addition to their role in evaporative cooling, urban trees also contribute to heat mitigation in urban microclimates through radiative shading effects (Georgi and Zafiriadis, 2006; de Abreu-Harbich et al., 2015; Upreti et al., 2017; Wang et al., 2018), whereby shortwave radiation is reflected towards the sky and surrounding surfaces. Upreti et al. (2017) simulated the radiative shading effect of urban trees in a regional built environment and predicted that the capacity of trees to reduce urban surface and air temperature was about $2-9{ }^{\circ} \mathrm{C}$ and $1-5{ }^{\circ} \mathrm{C}$, respectively. Monte Carlo ray tracing methods have commonly been used in urban multilayer radiation models to factor in urban tree radiative shading effects with simplified 2D simulation (Krayenhoff et al., 2014; Wang, 2014; Upreti et al., 2017). Essentially, validation of radiative exchange models with trees has been limited due to lack of experimental measurements of radiation within canyons in urban communities (Krayenhoff et al., 2014), which has lead to simplification of modelling approaches. Furthermore, models have typically assumed a spherical leaf angle distribution and a fixed extinction coefficient (e.g. 0.5) for tree intercept radiation (Krayenhoff et al., 2014; Park et al., 2019), meaning that tree radiative performance is modeled as being fixed and invariant with time. Although other microclimate modelling studies have employed complicated 3D CFD (Computational Fluid Dynamics) calculations in ENVI-met with the intention of taking the tree radiative shading effect into account (Wu and Chen, 2017; Eckmann et al., 2018; Zhang et al., 2018; Zhao et al., 2018; Wu et al., 2019), tree crown surface albedo has been considered constant for any given species. Hence, it is important to examine 
whether these commonly applied assumptions about tree leaves and crowns are in fact correct.

Generally, previous research into urban microclimate modelling and the development of urban tree planning strategies has used simplified approaches to assess tree radiative shading effects (Lee and Park, 2008; Wang, 2014; Upreti et al., 2017; Zhang et al., 2018; Eckmann et al., 2018; Simon et al., 2018). Tree crown surface albedo for a species is commonly assumed to be a constant in microclimate environment modelling (Eckmann et al., 2018) and in developing urban planning strategies (Zhang et al., 2018); however, temporal variation in tree crown transflectance throughout a day has been demonstrated (Deng et al., 2020). Therefore, to better understand urban tree radiative shading effects, the radiative performance within and between multiple tree species should be examined more closely, especially in the infrared (IR) region.

Previously, we established a methodology to characterise the IR radiative performance of urban trees by in-situ tree crown spectroscopy (Deng et al., 2019), and employed the method to solve two research questions (Deng et al., 2020): determining the spatial distribution of tree crown transflectance for individual trees, and identifying interspecific differences in tree radiative performance in the IR region. We found that the spatial distribution of a tree's radiative performance varied with solar time and solar altitude, and that interspecific differences in tree radiative performance levels in the IR 
region were strongly dependent on leaf size in dense foliage (i.e. foliage with no obvious gaps and no concave shapes in tree crown contours) (Deng et al., 2020). Based on this previous work, the present study was designed with the following aims: i) to further identify the spatial distribution profile and temporal variation in tree radiative performance during the northern hemisphere summer by combining in-situ spectroscopy and spectroradiometry, ii) to elucidate the relationship between tree crown mean transflectance in the NIR (Near Infrared) region of $800-900 \mathrm{~nm}$ and tree crown surface albedo by combining in-situ spectroscopy and shortwave radiometry, and iii) to examine whether temporal variation in the tree crown surface albedo varies across different species. Each of these aims was intended to provide useful information for future urban microclimate modelling and the development of appropriate urban tree planning strategies.

\section{Measurement methods and test conditions}

\subsection{In-situ tree crown spectroscopy and shortwave radiometry}

In our previously established protocols for characterising the radiative performance of urban trees (Deng et al., 2019), the term tree crown transflectance $(\tau R)$ or transflection was adopted. Here, transflection of shortwave radiation from the tree crown refers to the comprehensive effect of transmitted and reflected shortwave radiation, rather than the individual processes of leaf reflectance or leaf transmittance alone. 
In the present study of tree crown transflectance across species, identical measuring instruments and test facilities were used as in our earlier work (Deng et al., 2020). Namely, a Black-Comet-SR model CXR-SR (StellarNET Inc., Tampa, Florida, USA) concave grating miniature spectrometer (wavelength range: $350-1000 \mathrm{~nm}$; spectral resolution: $0.5 \mathrm{~nm}$; field of view of the fiber-optic cable: $25^{\circ}$ ) was attached to an $8 \mathrm{~m}$ tripod to carry out field tests. The tripod was scalable and facilitated raising the spectrometer fiber-optic cable up to a maximum of $8 \mathrm{~m}$ and in any direction, as shown in Figure 1 (a). The miniature spectrometer had a spectroradiometer mode for in-situ spectroradiometry; by fitting a cosine receptor to the fiber-optic tip it was able to measure solar irradiance spectra in a field of view of $180^{\circ}$ in the measuring wavelength range. Solar irradiance spectra were usually measured synchronously with the tree crown transflectance spectra for normalisation, using the spectroradiometer mode of the miniature spectrometer. Reference spectra in tree crown transflectance measurement were sampled by employing a white reflectance standard RS50 (see

\section{Figure 1 (a)).}

For the shortwave radiometry, a model SN-500 net radiometer (Apogee Instruments, USA) with a field of view of $150^{\circ}$ and calibration uncertainty of $\pm 5 \%$ was used to measure four radiation components (incoming shortwave, outgoing shortwave, incoming longwave, outgoing longwave) and net radiation (shortwave and longwave). A model SI-431-SS infrared radiometer (Apogee Instruments, USA) with an ultra- 
narrow field of view of $28^{\circ}$ was used to record tree leaf temperature in the measuring patches in the tree crown. The net radiometer and the infrared radiometer were fixed to a $4.2 \mathrm{~m}$ height (adjustable) tripod mast, as shown in Figure 1 (b). As the length of the data communication cable was $4 \mathrm{~m}$, the radiometers could reach a maximum vertical height of $4.2 \mathrm{~m}$. It was not convenient to sample shortwave radiation with the radiometers in different directions due to limitations of the cable length and the tripod mast. As the net radiometer had a field of view of $150^{\circ}$, it was kept $30-40 \mathrm{~cm}$ away from the sampling patches in the tree crown to guarantee the measurement accuracy.

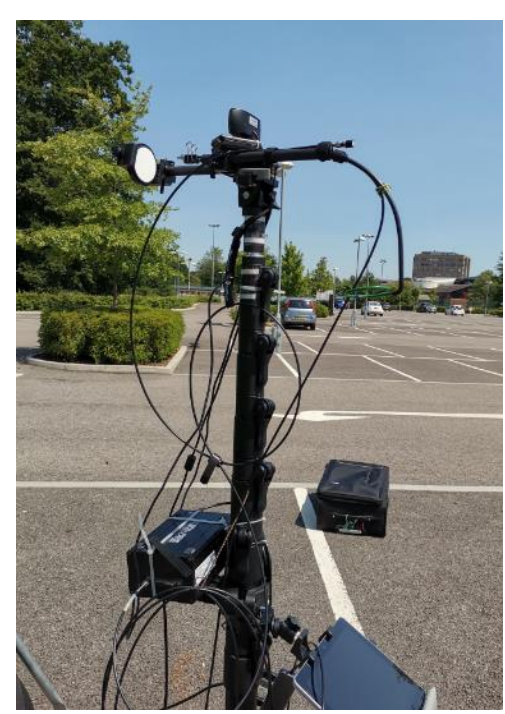

(a)

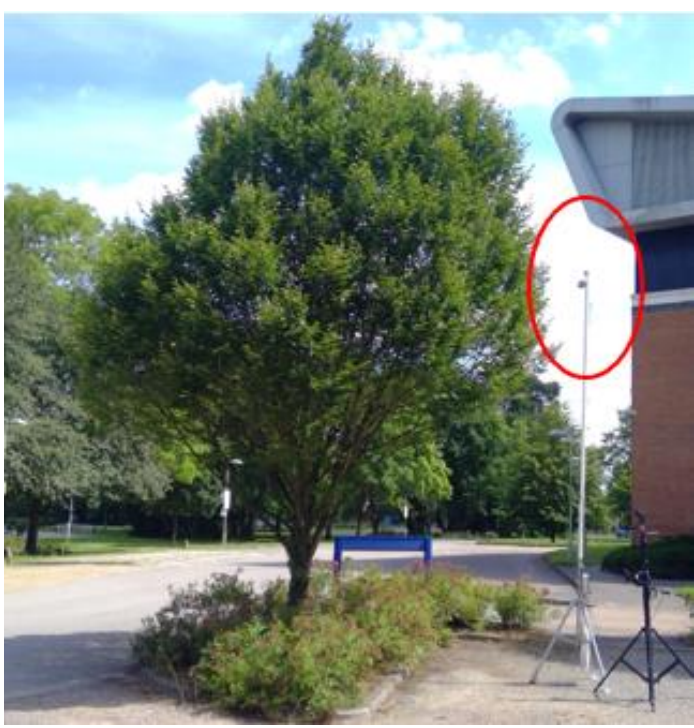

(b)

Figure 1. Deployment of experimental equipment. (a) Miniature spectrometer with a spectroradiometer mode held by a scalable $8 \mathrm{~m}$ maximum height tripod for in-situ tree crown spectroscopy; (b) Net radiometer and infrared radiometer fixed on a $4.2 \mathrm{~m}$ height (adjustable) tripod mast for in-situ radiometry. 


\subsection{Test conditions}

177 Isolated trees of the species Carpinus betulus (Fastigiate Hornbeam; deciduous), Acer campestre (Field Maple; deciduous), and Taxus baccata (English Yew; evergreen) were sampled in an open field on sunny days in June to August 2020 at the Whiteknights campus, University of Reading $\left(51.44^{\circ} \mathrm{N}, 0.94^{\circ} \mathrm{W}\right)$, UK. These species were selected because all three are small to medium sized shade-tolerant trees, native to the UK and Europe, that are commonly planted in urban areas as single trees, groups, or hedgerows

183

(Benham et al., 2016; Sikkema et al., 2016; Zecchin et al., 2016). Operationally, the relatively lower heights of these species, and the ease of access to individuals in open areas, made them very convenient for in-situ tests measuring the spatial distribution of tree crown transflectance. The heights of the sampled trees were in the range of $4.5-$ $7.0 \mathrm{~m}$. A sampling distance of $2.0-5.0 \mathrm{~m}$ away from the tree crown contours was chosen in tests. Our earlier tests indicated that a measuring distance of $2.0-5.0 \mathrm{~m}$ from the tree crown contours to the spectrometer fiber-optic tip was most appropriate for the USB camera, excluded specular reflection from tree leaves, and made the measuring results more robust (Deng et al., 2020). Tree crown transflectance spectra in $350-1000$ $\mathrm{nm}$ were sampled in a vertical loop around the tree crown and aligned with the solar azimuth direction (abbreviated as 'a typically vertical loop' hereafter) at ten measuring points in different directions (see Figure 2). The reference spectrum was always measured in the momentary solar azimuth direction (Deng et al., 2019). 
197 Conditions of fixed solar altitude were chosen in order to identify the spatial distribution

198 profile of tree radiative performance in terms of the tree crown transflectance spectra,

199 as it was shown that the spatial distribution of a tree's radiative performance varies

200 temporally with solar altitude (Deng et al., 2020). Scenarios of different solar altitudes

201 were considered to examine temporal variation in tree radiative performance. The tree

202 crown transflectance spectra in the typically vertical loop were usually sampled from

203 visibly dense foliage with no gaps in the tree crowns in the view vison, though

204 occasionally a concave crown contour appeared in the tree crown. As visibly dense

205 foliage was usually sampled, any background noise signal for the tree crown

206 transflectance spectra sampling was disregarded according to the demonstration in our

207 earlier work (Deng et al., 2020).

208

To determine the relationship between mean tree crown transflectance in the NIR region

210 and tree crown surface albedo, in-situ spectroscopy and shortwave radiometry were

combined. Both the tree crown transflectance and the solar irradiance spectra were sampled simultaneously using the spectrometer at a point $2.5-4.0 \mathrm{~m}$ away from the sampled tree crown in a horizontal view, whereas incoming and outgoing shortwave

214 radiation from the tree crown were measured by the net radiometer at a point $30-40$

$215 \mathrm{~cm}$ away from the tree crown contour and at the same height as that of the spectrometer sensors. 


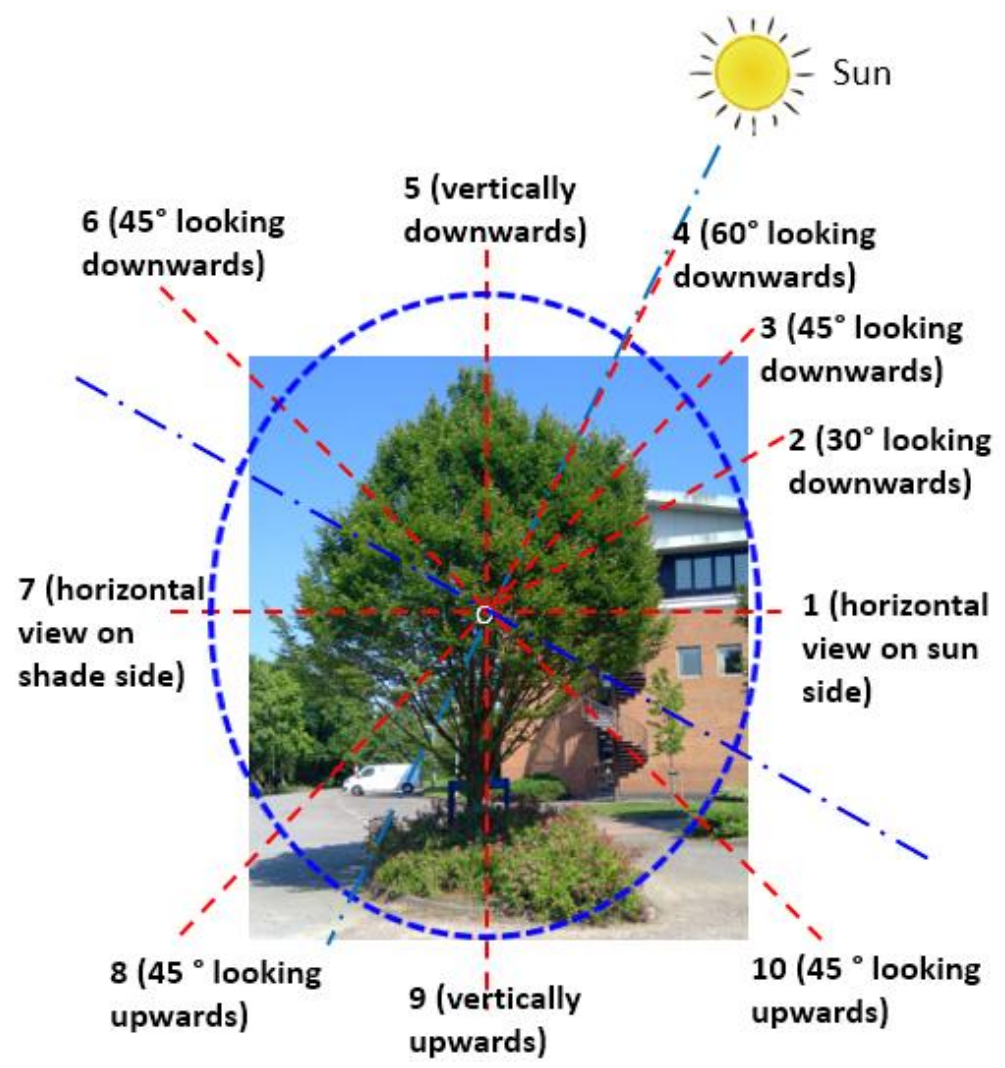

Figure 2. Illustration of the sampling directions/locations in a vertical loop around the in an open space (car park)

\section{Results and discussion} reference plane

As noted in the test conditions above, fixed solar altitudes were chosen to sample the tree crown transflectance spectra, employing a vertical reference white plane. Field tests were implemented for Carpinus betulus (Fastigiate Hornbeam) and Acer campestre 
(Field Maple) on sunny days between 12:15 - 14:00 (GMT; British Summer Time), when the solar altitude was approximately constant. Ten measuring points in the typically vertical loop around the tree crown aligned with the solar azimuth direction, as illustrated in Figure 2, were sampled to identify the spatial distribution profile of tree radiative performance. Figure 3 (a) provides the sampled tree crown transflectance spectra of a single Carpinus betulus in different directions at solar altitude $\alpha=61^{\circ} \pm$ $1^{\circ}$ on 25 June 2020 at Reading, UK. It is evident that the tree crown transflectance spectrum in the IR region with a viewing angle of $60^{\circ}$ (point ' 4 ') has the highest level, followed in descending order by the IR transflectance spectra with viewing angles of $45^{\circ}$ (point ' 3 '), $30^{\circ}$ (point ' 2 '), and $90^{\circ}$ (point ' 5 '). The IR transflectance spectra were at the lowest level in the shade areas (points ' 7 ', ' 8 ', '9').

To intuitively display the spatial distribution of tree crown transflectance in the typically vertical loop around the tree crown, mean transflectance in the NIR region of $800-900 \mathrm{~nm}\left(\tau R_{\text {mean }, 800-900}\right)$ was adopted as an indicator, because tree crown transflectance spectra in the NIR region $(800-900 \mathrm{~nm})$ tended to be relatively invariant and held the maximum spectral transflectance in the full wavelength range. The relation of $\tau R_{\text {mean }, 800-900}$ to tree crown surface albedo will be discussed further in section 3.4.

Figure 3 (b) delineates the spatial distribution profile of tree crown transflectance in the typically vertical loop at solar altitude $\alpha=61^{\circ} \pm 1^{\circ}$ in terms of $\tau R_{\text {mean,800-900. }}$. Here the mean transflectance $\left(\tau R_{\text {mean,800-900 }}\right)$ was approximately symmetric along the 
axis in the solar altitude direction (noted as 'symmetric axis' hereafter). Maximum mean transflectance occurred at point ' 4 ' along the symmetric axis (see Figure 3 (b)), as the solar irradiance in this direction (i.e. direct normal solar radiation) was larger than in all other directions. This phenomenon was commonly observed for different tree species, as long as the tree crown transflectance spectra were sampled on the patches of tree crowns with visibly dense foliage (i.e. no gaps in foliage, no concave crown contours). It was confirmed in our previous work (Deng et al., 2020) that sparse foliage and concave shapes in the tree crowns degraded the tree crown transflectance levels.

To better understand the spatial distribution profile of transflectance in Figure 3 (b), it is necessary to introduce another principal axis perpendicular to the symmetric axis (hereafter noted as 'perpendicular axis'), which aids in distinguishing between characteristics of the transflected radiation in the sunlit area and in the shade area. As sunlight struck the region above the perperdicular axis towards the sky ('the sunlit area'), transflected radiation from the tree crown in this region was significantly higher than that in the region below the perpendicular axis ('the shade area'). Since solar radiation only has component vectors in the sunlit area, it is presumed that the transflected shortwave radiation from the tree crown in the sunlit area is dominated by reflected radiation, while the transflected radiation in the shade area is contributed by transmission through multiple layers of tree leaves as well as minor background reflection (e.g. coming from the ground surface or surrounding environment). 


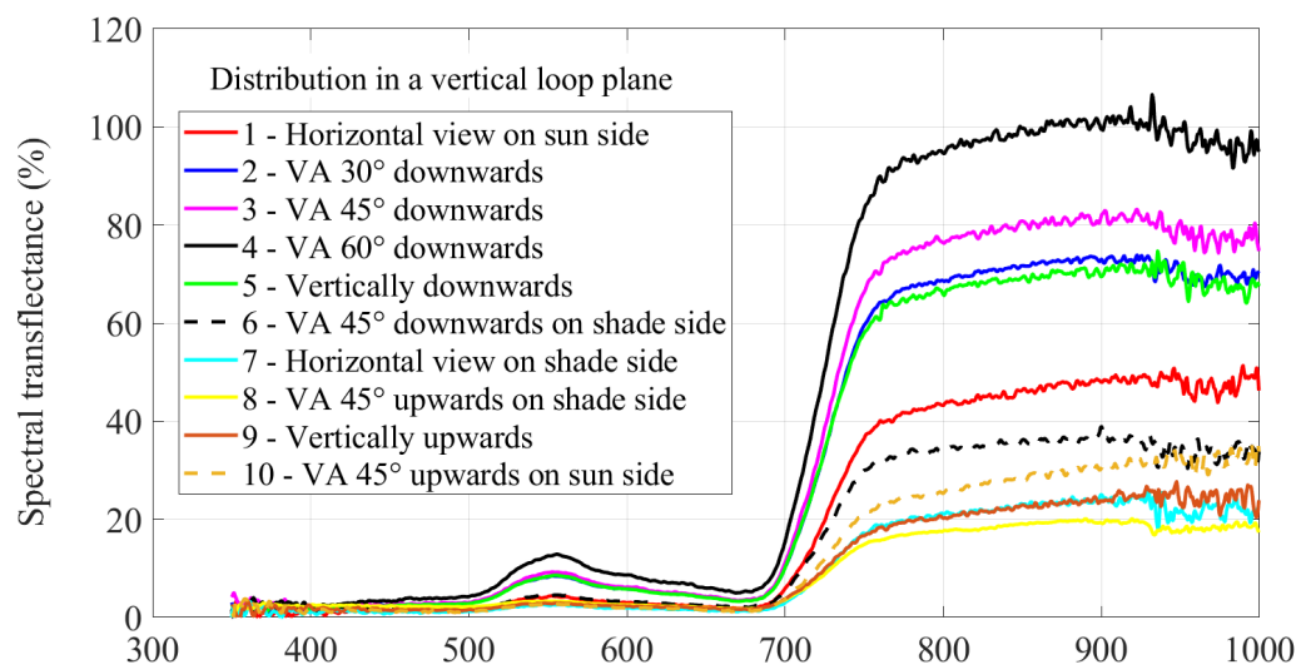

272 (a)

Wavelength (nm)

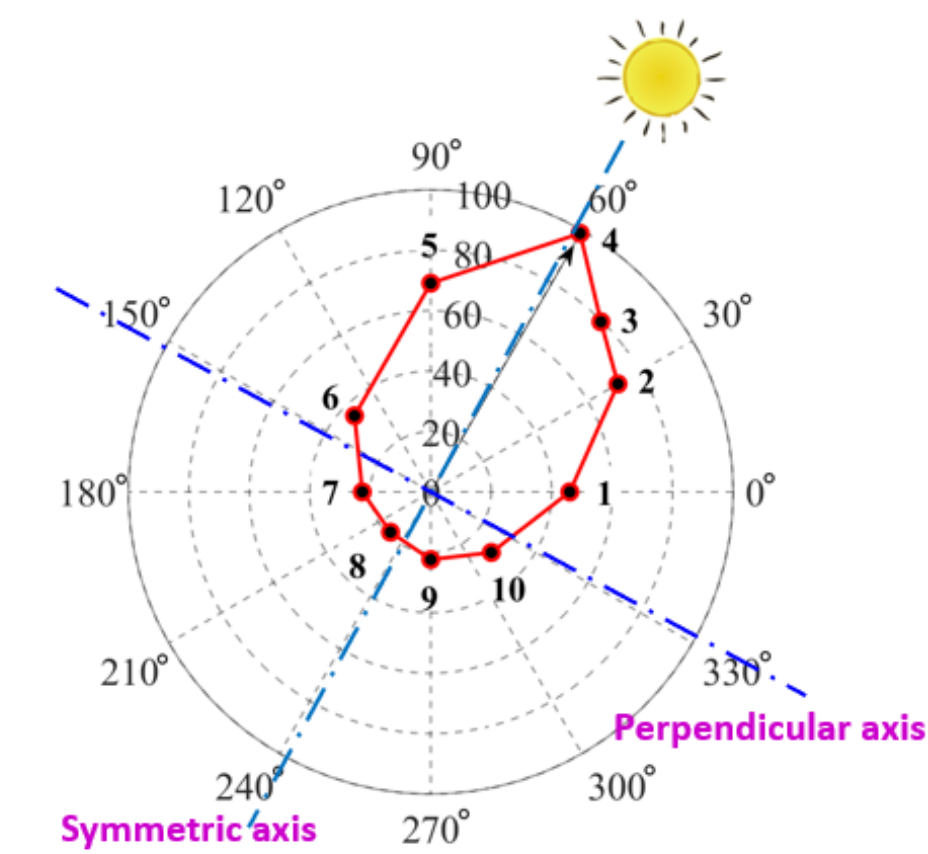

273 (b)

274 Figure 3. Test results of a single Carpinus betulus. (a) Tree crown transflectance spectra

275 at different sampling directions in the vertical loop around the tree crown in concert

276 with the solar azimuth direction at solar altitude $\alpha=61^{\circ}\left( \pm 1^{\circ}\right)$; (b) Spatial distribution profile of the mean transflectance in the NIR region of $800-900 \mathrm{~nm}$ in the vertical $278 \quad$ loop 
280 The approximate symmetry in the spatial distribution profile of mean transflectance in 281 the $800-900 \mathrm{~nm}$ range along the symmetric axis of Carpinus betulus was also observed 282 in Acer campestre and Taxus baccata. Figure 4 (a) and (b) shows an isolated Acer campestre sampled in an open space and the spatial distribution profile of the mean transflectance in $800-900 \mathrm{~nm}$ range in the vertical loop around the tree crown at solar

285 altitude $\alpha=56^{\circ}$. The spatial distribution profile was approximately symmetric in the 286 solar altitude direction, except at point ' 6 ' where a concave contour appered in the view 287 vision of the sampling patch in the tree crown (see Figure 4 (a)). The concave crown 288 contour degraded the transflected radiation at point ' 6 '. It was also confirmed that for 289 different species, transflected shortwave radiation from the tree crown in the sunlit area 290 (above the perpendicular axis towards the sky) was dominated by reflection, while that 291 in the shade area (at the lower part of the tree crown below the perpendicular axis) was jointly determined by transmission and minor background reflection. 
(a)
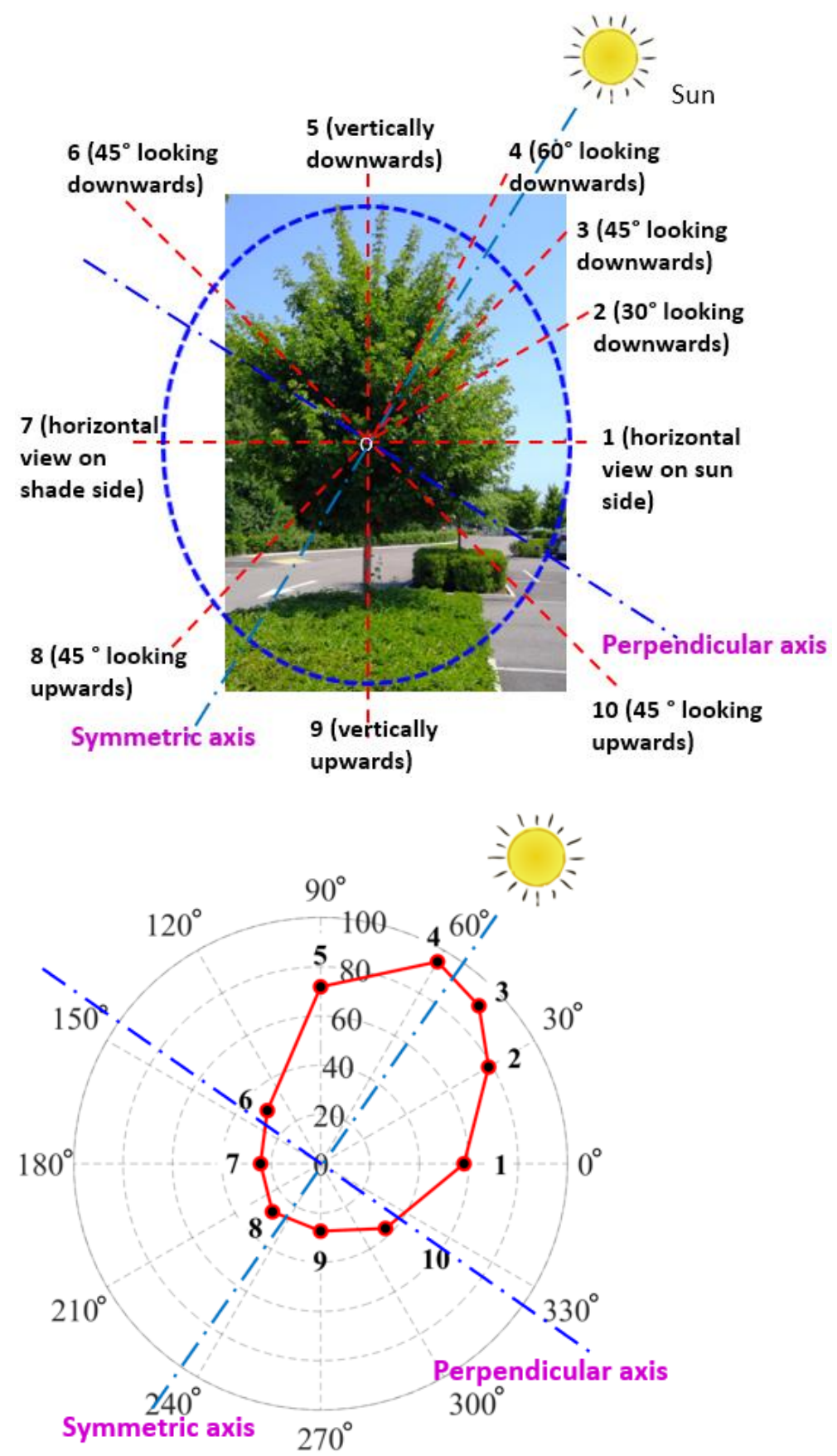

(b) $800-900 \mathrm{~nm}$ mean transflectance (\%)

Figure 4. Experimental tree and results of spectral measurement. (a) Isolated Acer 
300

301

302

303

304

305

306

307

308

309

310

311

312

313

314

315

3.2 Spatial distribution profile of tree radiative performance in terms of normalised transflectance in the sunlit area

The tree crown transflectance $(\tau R)$ spectra sampled at different viewing angles of the spectrometer fiber-optic tip (VA $=30^{\circ}, 45^{\circ}, 60^{\circ}$ and $90^{\circ}$ looking downwards) with a vertical reference spectrum can be normalised to equivalent transflectance spectra. This is achieved by converting the vertical reference irradiance spectra to corresponding solar irradiance spectra in the incoming solar radiation direction with viewing angles of the sampled transflectance spectra. The normalised transflectance spectrum is calculated in Equation (1).

Figure 5 (a) gives the solar irradiance spectra at different viewing angles (VAs) synchronously measured at solar altitude $\alpha=61^{\circ}$ on the sunny day of 25 th June 2020 for normalising the tree crown transflectance in the sunlit area in Figure 3 (a). Figure 5 (b) displays the normalised transflectance spectra in the sunlit area for the Carpinus betulus sampled in the typically vertical loop around the tree crown at solar altitude $\alpha=61^{\circ}\left( \pm 1^{\circ}\right)$. The result indicates that the normalised transflectance spectra at different viewing angles in the sunlit area turn out to be nearly the same, irrespective of minor measurement errors due to measuring angle deviation. This mainly occurs 
because diffuse reflection dominates the tree crown transflection in the sunlit area. It is inferred that measurements taken from sampling patches in the sunlit area with different viewing angles at various heights with visibly dense foliage tends to have nearly the same normalised transflectance. As the momentary solar irradiance in the solar altitude direction is maximum, transflected shortwave radiation from the tree crown in the solar altitude direction turns out to be the greatest compared to other directions, except where gaps in foliage or concave crown contours appear.

For tree crown transflectance in the shade area, the interaction mechanism was different from that in the sunlit area. Apart from transmitted radiation passing through multiple layers of tree leaves in the tree crown, it was observed that secondary reflected radiation from the lower part of the tree crowns deriving from (sealed or paved) ground surfaces was on the same order of magnitude as the transmitted radiation through leaves. As shown in Figure 5 (a), the magnitude of solar irradiance measuring from point ' 6 ' towards the sky was comparable to that from the ground surface to point ' 10 '. Normalising tree crown transflectance consistently at point ' 6 ' would result in a much greater transflectance level compared to the normalised transflectance in the sunlit area. Note that point ' 6 ' was $74^{\circ}$ counterclockwise deviated from the solar altitude at $61^{\circ}$ and close to the shade area. It was presumed that point ' 6 ' was in the transitional region between the sunlit area and the shade area. Additionally, it did not make sense to normalise the tree crown transflectance in the shade area (points ' 7 ', ' 8 ', ' 9 ', ' 10 ') using 
342 greater transflectance as well. Due to these observations, the vertical reference spectrum

343 was not changed in the normalised spatial distribution profile for the tree crown 344 transflectance in the shade area or in the transitional region between the shade area and 345 the sunlit area.

346

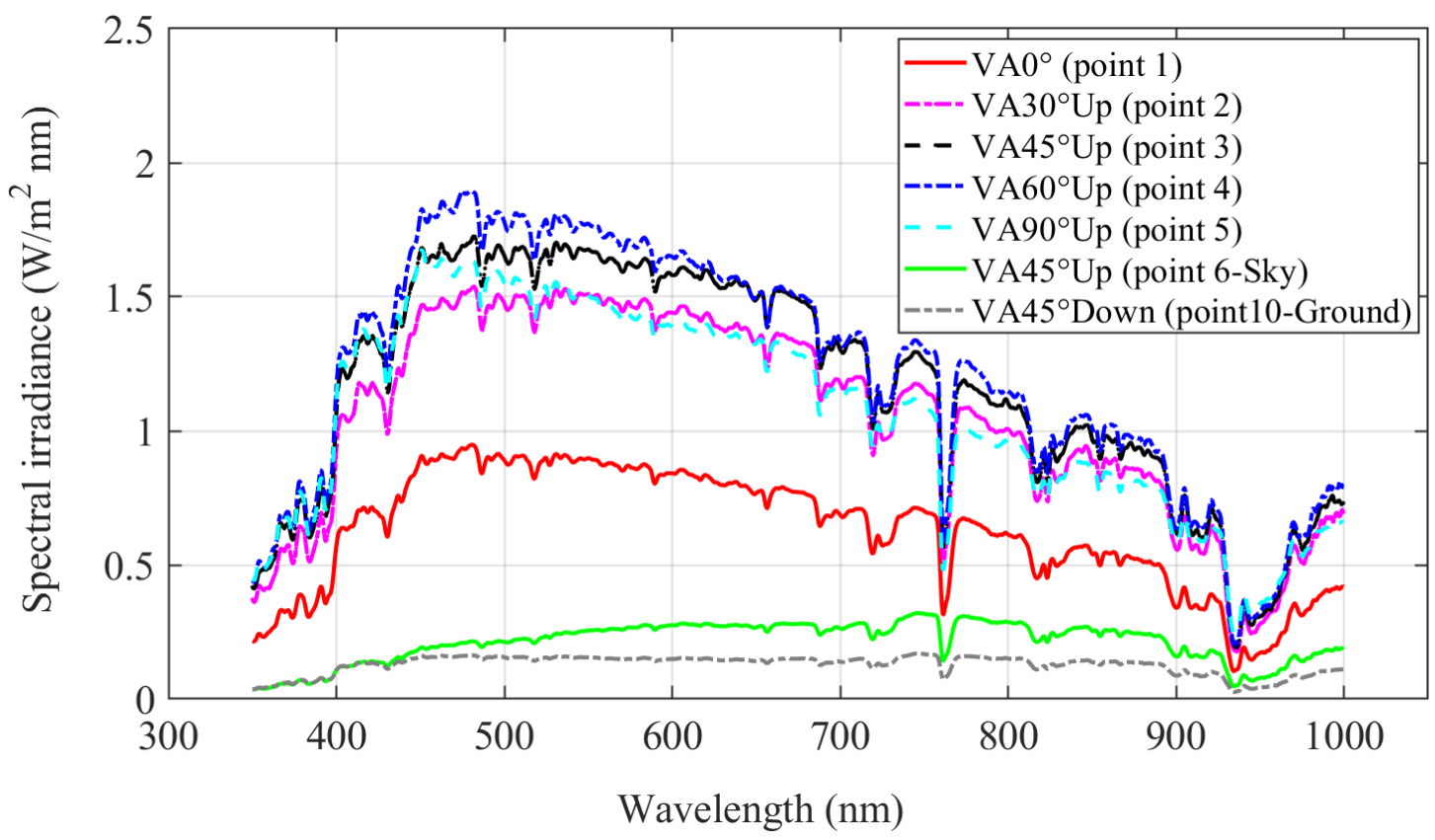




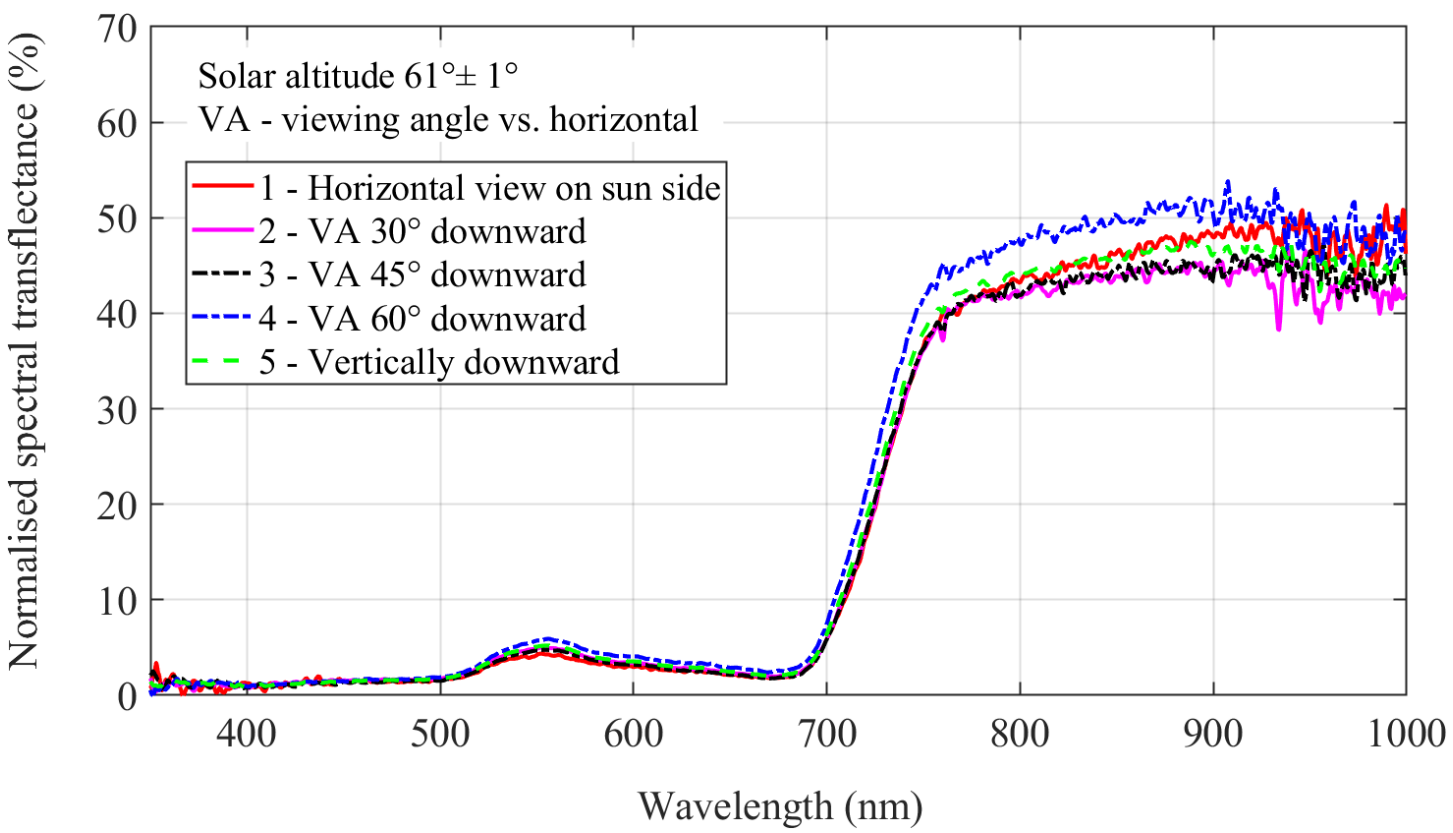

Figure 5. Normalisation of tree crown transflectance spectra at different viewing angles.

(a) Solar irradiance spectra at different viewing angles; (b) Normalised transflectance spectra of Carpinus betulus in the sunlit area

Based on the transflectance normalisation principle stated above, the spatial distribution profile of tree radiative performance in terms of the normalised transflectance in the sunlit area was obtained via Equation (1). Figure 6 (a) displays the spatial distribution of the mean transflectance in the $800-900 \mathrm{~nm}$ range with normalised transflectance in the sunlit area for the Carpinus betulus sampled in the typically vertical loop at solar altitude $\alpha=61^{\circ}\left( \pm 1^{\circ}\right)$, in contrast to the spatial distribution profile with a united vertical reference spectrum in Figure 3 (b). As seen in Figure 6 (a), the normalised mean transflectance in the $800-900 \mathrm{~nm}$ range in the sunlit area (except point ' 6 ' which 

chart.

was close to the shade area and was regarded as being in the transitional region) forms a big circular arc, while the mean transflectance in the shade area (points ' 7 ', ' 8 ', ' 9 ') forms a relatively smaller circular arc, with transitional regions between the sunlit area and the shade area. The ideal spatial distribution profile and four quadrants of the mean transflectance in the $800-900 \mathrm{~nm}$ range were drawn in Figure 6 (b). The ideal profile was determined by experimental data points and understanding of spatial tree radiative performance in terms of IR transflectance in the sunlit area, the shade area, and the transitional regions. The transflectance at different viewing angles was normalised in the majority of quadrants I \& II (the sunlit area), while the vertical reference spectrum was kept for the transflectance in quadrants III \& IV and the transitional regions. The whole profile looked like a 'mushroom' at a tilted angle of the momentary solar altitude $(\alpha)$. Note that the determination of the ideal mushroom chart was based on normalised transflectance in the sunlit area with visibly dense foliage being sampled. If there were gaps in foliage or concave shapes in the tree crowns, real distribution profile for individual trees would have local concave shapes compared to the ideal mushroom 


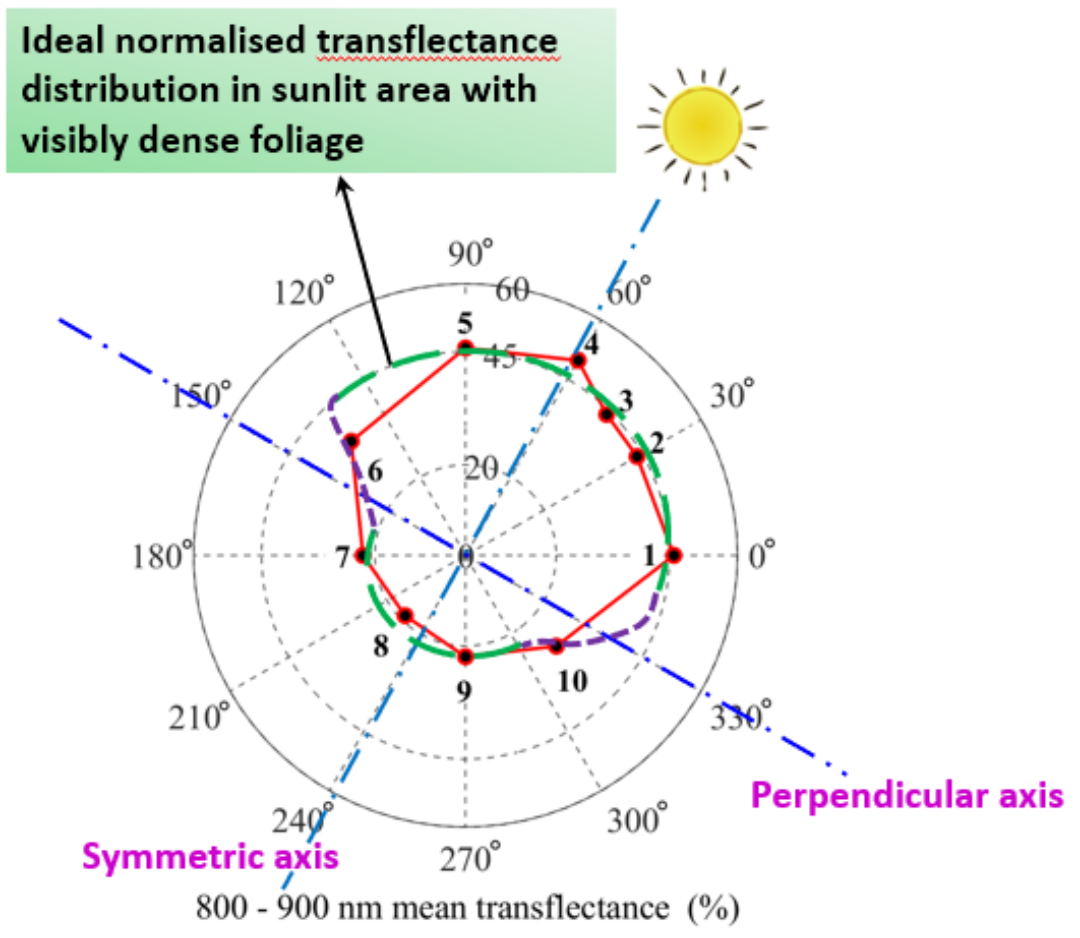

(a)

Solar altitude $\alpha=61^{\circ} \pm 1^{\circ}$

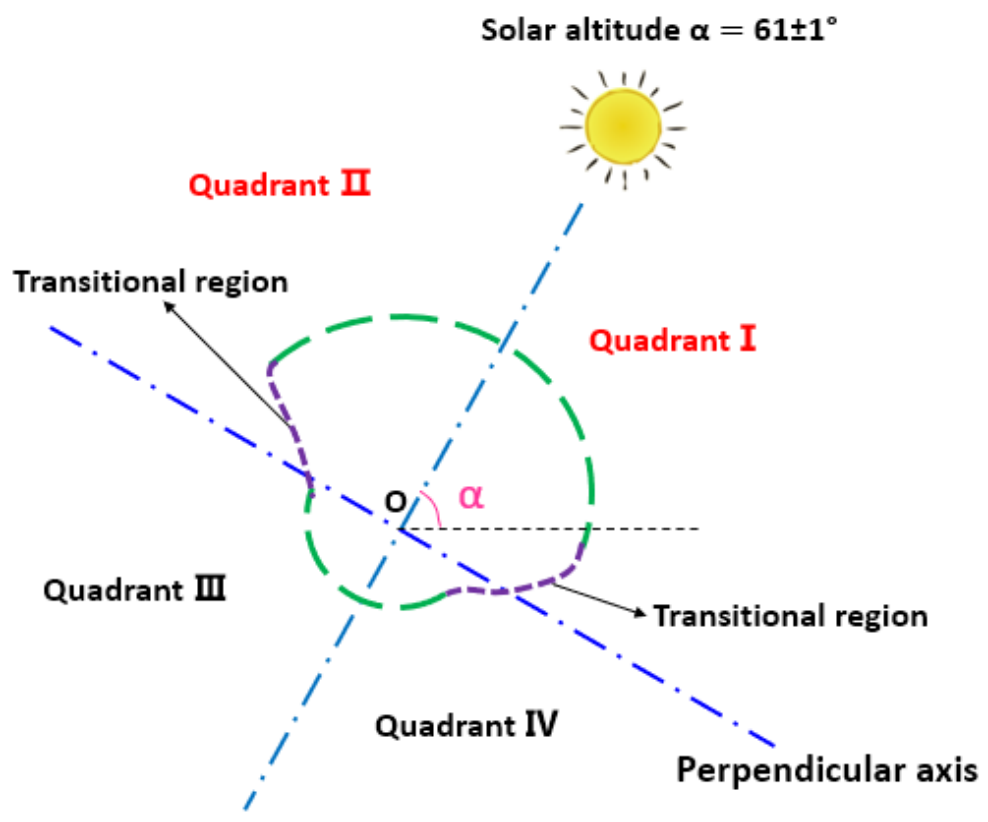

Symmetric axis

381 (b)

Figure 6. (a) Spatial distribution of mean transflectance in the $800-900 \mathrm{~nm}$ range with normalised transflectance in the sunlit area for the Carpinus betulus tree sampled in the vertical loop around the tree crown at solar altitude $\alpha=61^{\circ}$; (b) Ideal spatial 
distribution profile and four quadrants of the mean transflectance in $800-900 \mathrm{~nm}$ range.

A similar spatial distribution profile of tree radiative performance in terms of normalised transflectance in the sunlit area was also observed in other species. For example, Figure 7 gives the spatial distribution profile of mean transflectance in $800-$ $900 \mathrm{~nm}$ with normalised transflectance in the sunlit area for the Acer campestre (Field Maple) sampled in the typically vertical loop around the tree crown at solar altitude $\alpha=56^{\circ}$. It suggests that different species with similar crown morphologies share the common feature of an ideal normalised spatial distribution profile at a fixed solar altitude. For tree species that have different tree crown morphologies (e.g. circle, elliptic, and triangle), to the best of our knowledge, different shapes only lead to differences in the area size of transitional regions (see Figure 6) and the arc length of normalised transflectance in the sunlit area. Taking Figures 6(a) and 7 as examples, in the measurements of transflectance (red line), we did not measure any locations between points ' 5 ' and ' 6 ', but if the tree crown was sparse in this area, we can assume that tree crown transflectance in this region would be lower compared to that in the sunlit area. This would result in a shorter arc length of normalised transflectance in the sunlit area. 


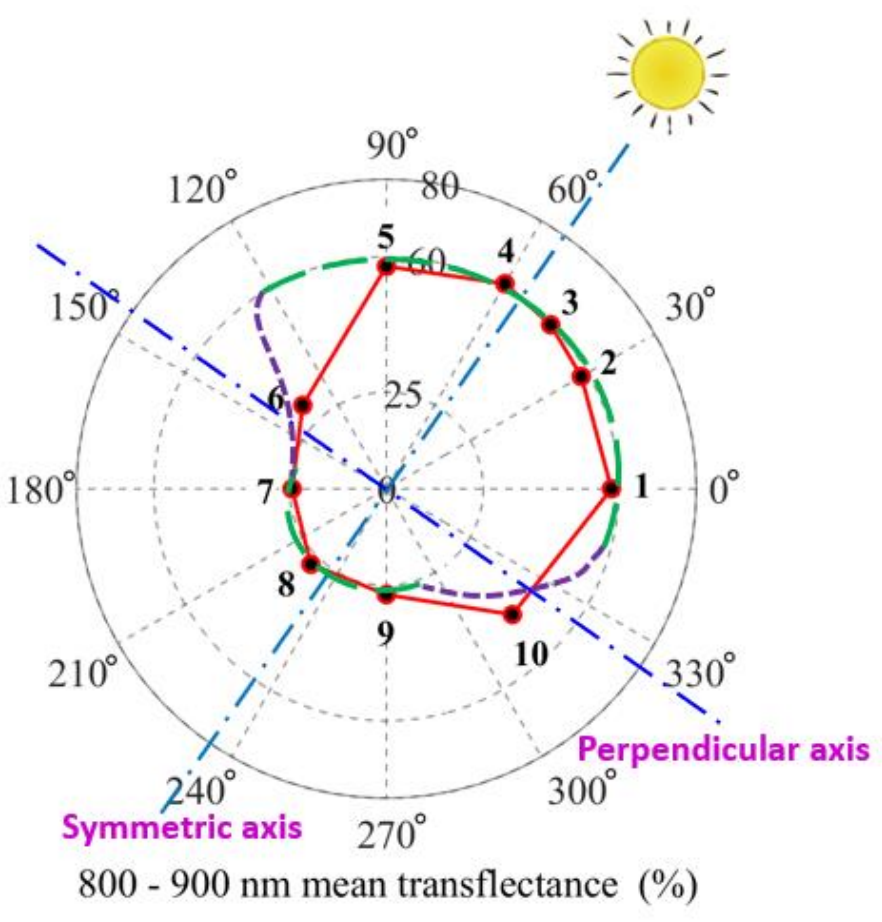

403

Figure 7. Spatial distribution profile of mean transflectance in $800-900 \mathrm{~nm}$ based on the normalised transflectance in the sunlit area for the Acer campestre sampled in the typically vertical loop around the tree crown at solar altitude $\alpha=56^{\circ}$

407

\subsection{Temporal variation of tree radiative performance}

409

410

411

412

413

414

415

As the spatial distribution of tree radiative performance varies with solar altitude (Deng et al., 2020), temporal variation in the spatial distribution profile of tree crown transflectance was ascertained. Figure 8 shows the temporal variation of the distribution of mean transflectance in the $800-900 \mathrm{~nm}$ range at two different solar altitudes $\alpha=45^{\circ}$ and $61^{\circ}$ for the Carpinus betulus sampled in the typically vertical loop with the vertical reference plane. It suggests that the transflected shortwave radiation from tree crowns at a lower solar altitude (in the morning or afternoon) is 
significantly lower than that at a higher solar altitude (at or close to solar noon) on a sunny day. To compare the difference quantitatively, the spatial distribution of mean transflectance in $800-900 \mathrm{~nm}$ sampled at solar altitude $45^{\circ}$ is displayed in Figure 9 (a) based on the normalised transflectance in the sunlit area. The normalised mean transflectance in $800-900 \mathrm{~nm}$ in the sunlit area at solar altitude of $45^{\circ}$ was $38.9 \%$, in contrast to $45.8 \%$ at solar altitude of $61^{\circ}$. The tree crown transflectance in the latter case was increased by $17.9 \%$ compared to the former one. Nevertheless, the spatial distribution profile of the mean transflectance based on the normalised transflectance in the sunlit area tended to be similar at solar altitude $\alpha=45^{\circ}$ and $\alpha=61^{\circ}$, except that tilted angles of the 'mushroom chart' were in concert with the momentary solar altitude (solar time), as shown in Figure 9 (b). The same pattern was noted for different tree species (e.g. compare the normalised distribution profile for Acer campestre in Figure 7 to that of Carpinus betulus in Figure 9).

Regarding the impact of solar altitude on the tree crown transflectance, our earlier work confirmed that the tree crown transflectance in the IR region within a species in the sunlit area was linearly associated with solar altitude on sunny days (Deng et al., 2020). Figure 10 provides the mean transflectance $(\tau R)$ in the $800-900 \mathrm{~nm}$ range vs. solar altitude $(\alpha)$ for tree species Carpinus betulus and Acer campestre. Supplementary data for Figure 10 is available in Appendix A. 


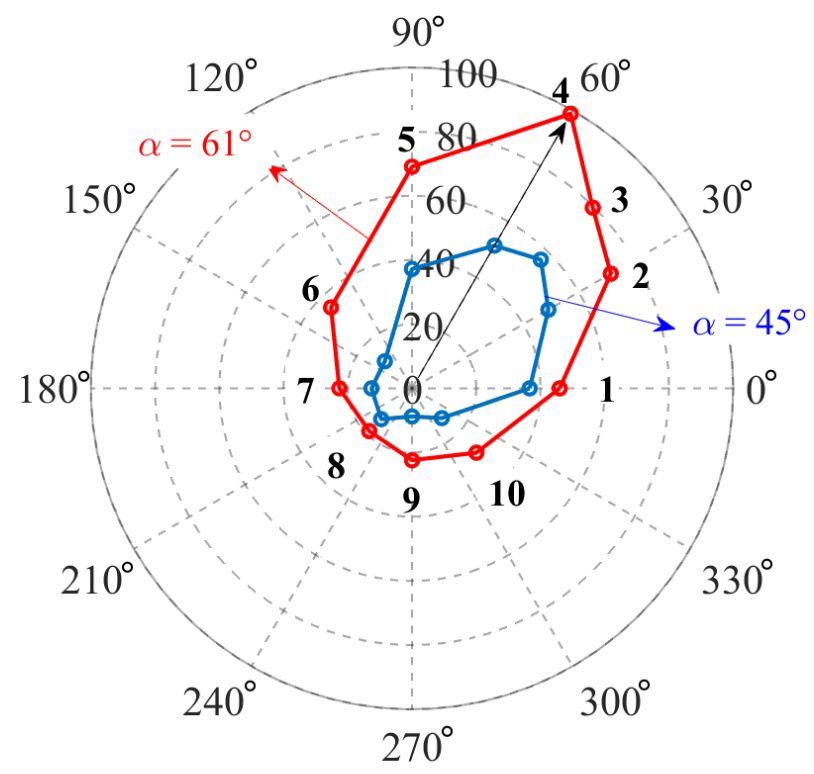

Figure 8. Temporal variation of the distribution of the mean transflectance in $800-$

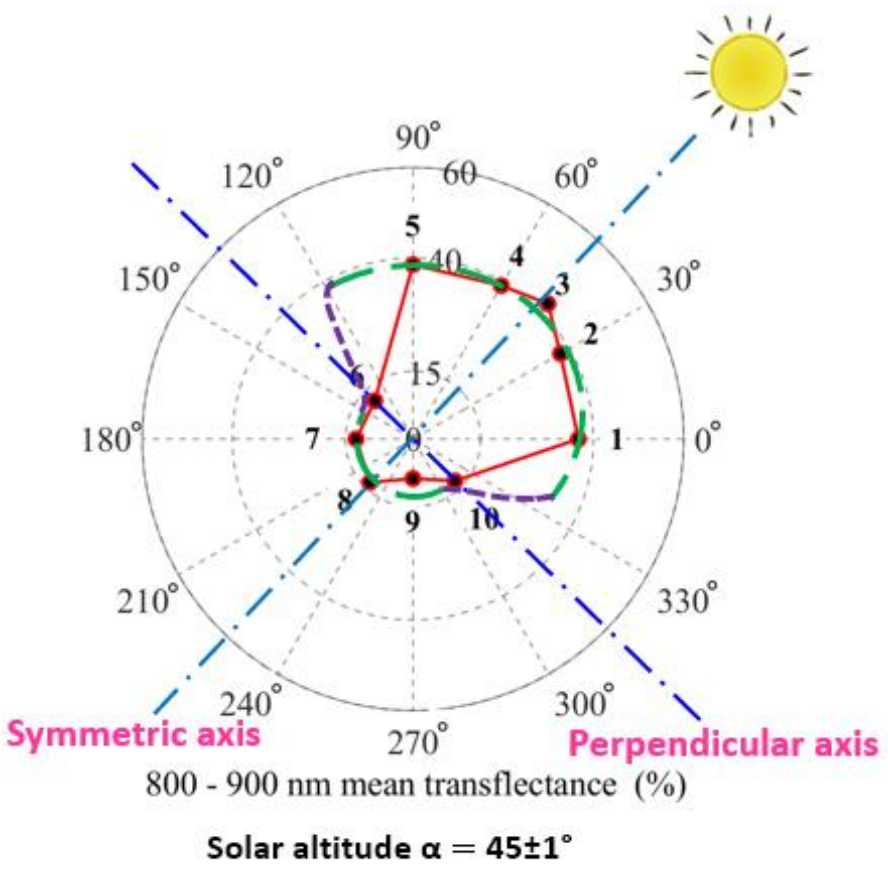

441

(a) 


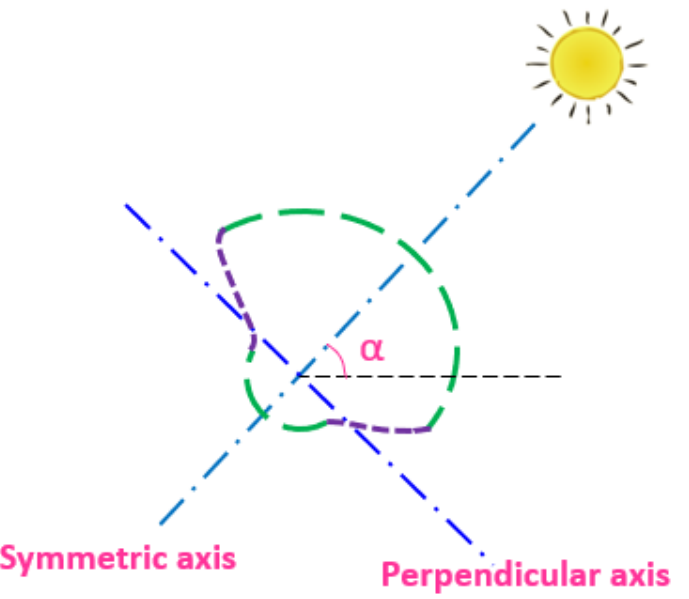

Solar altitude $\alpha=45^{\circ} \pm 1^{\circ}$

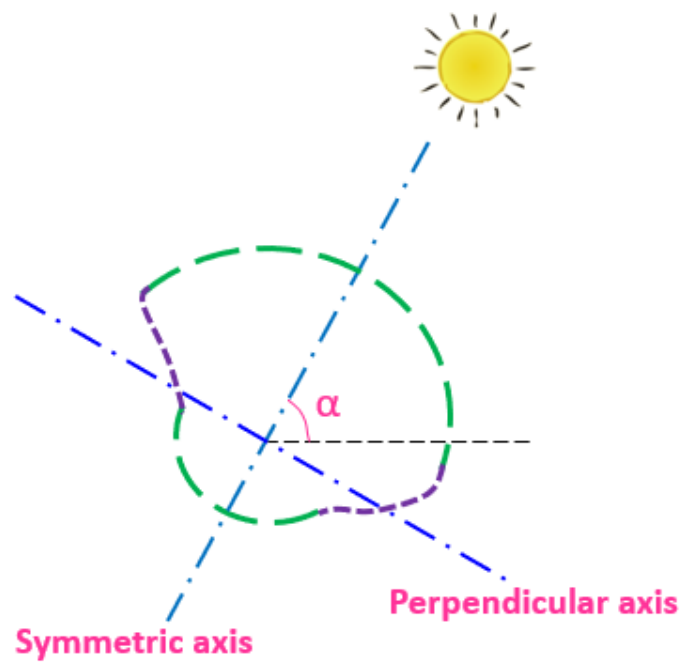

Solar altitude $\alpha=61^{\circ} \pm 1^{\circ}$

(b)

445 Figure 9. (a) Spatial distribution of mean transflectance in $800-900 \mathrm{~nm}$ based on normalised transflectance in the sunlit area for the Carpinus betulus sampled in the

447 typically vertical loop around the tree crown at solar altitude $\alpha=45^{\circ}$; (b) Comparison of spatial distribution profile of the mean transflectance at solar altitude $\alpha=45^{\circ}$ and 


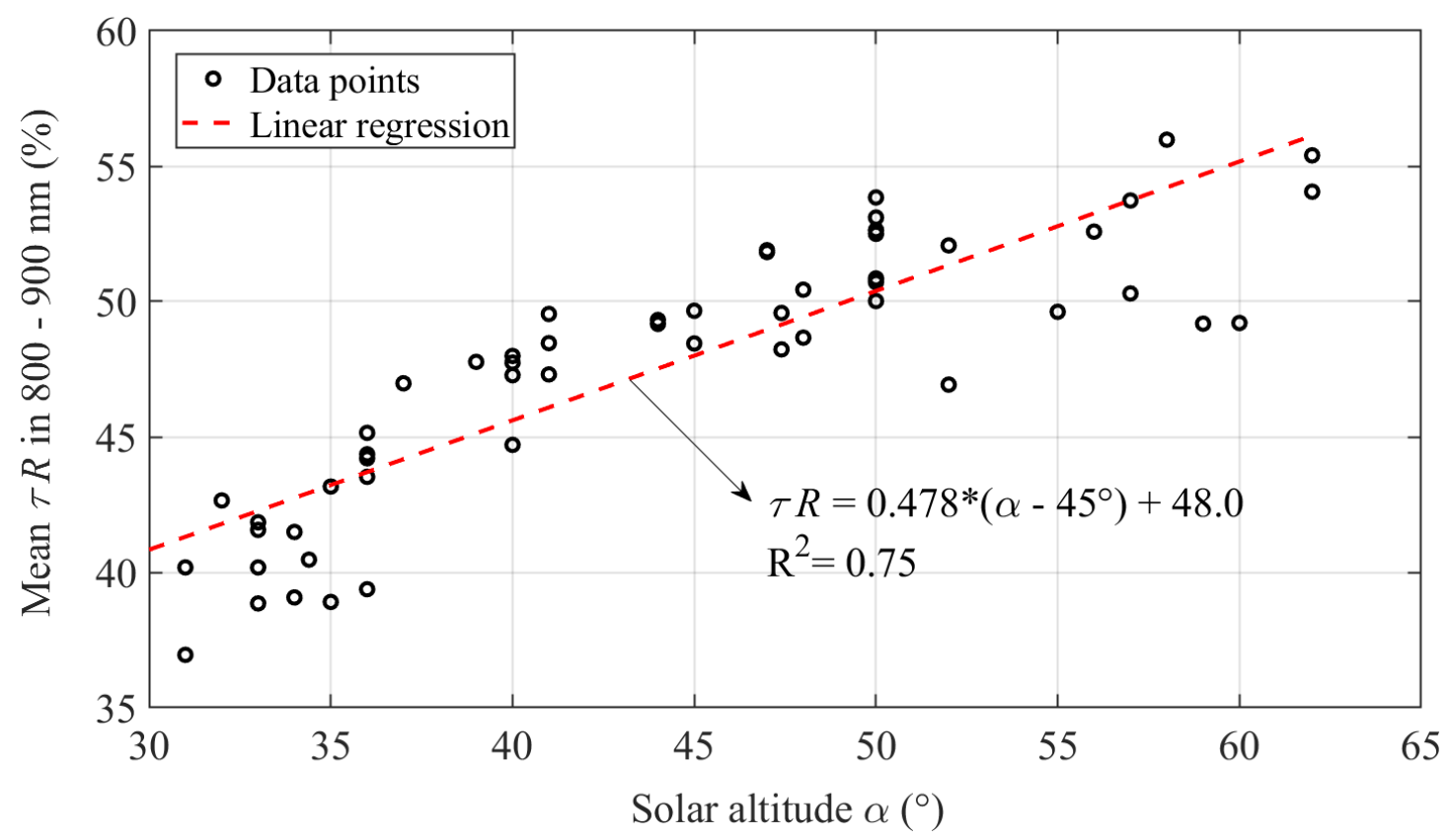

$452 \quad$ (a)

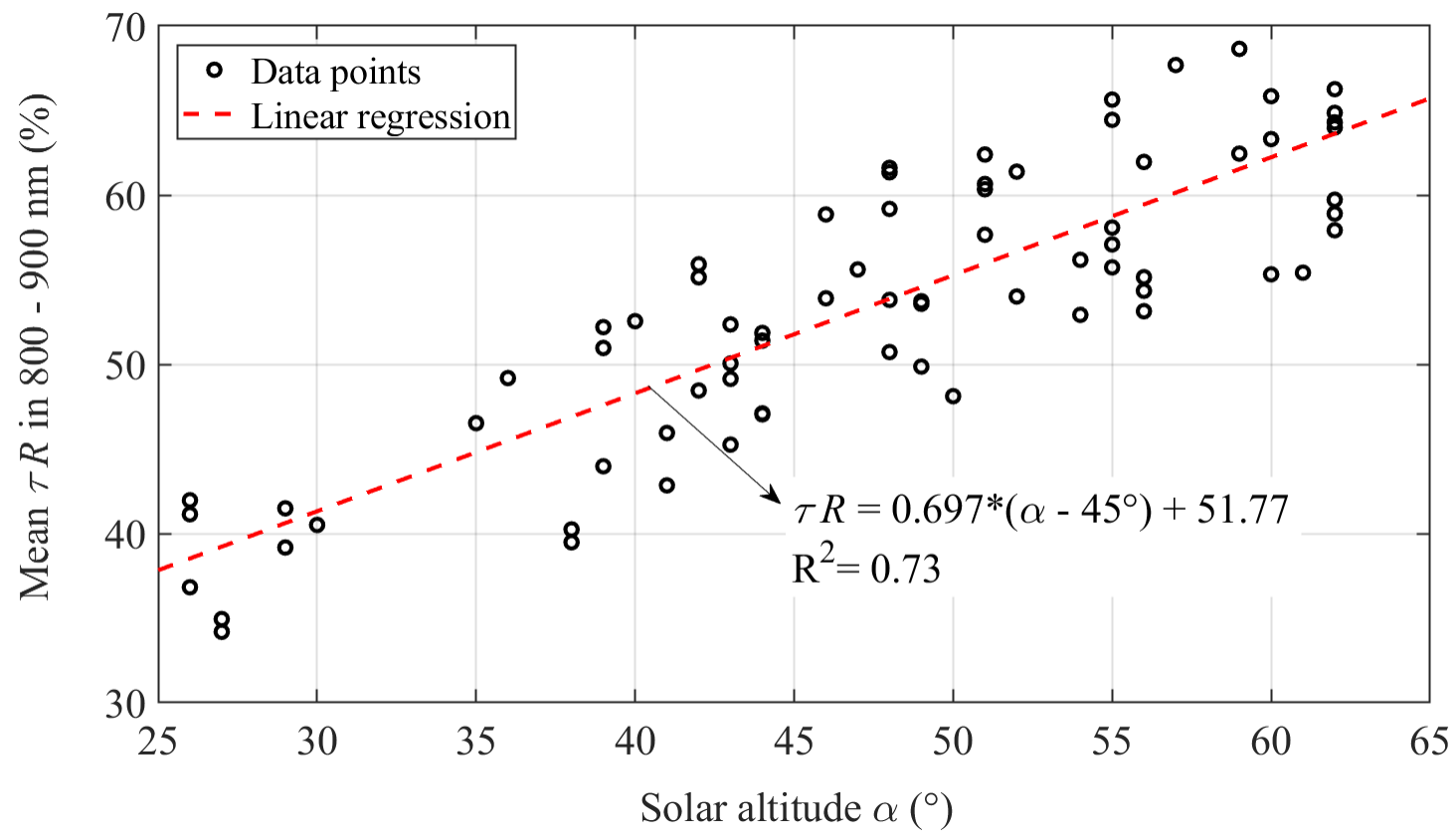

454 (b)

455 Figure 10. Mean transflectance $(\tau R)$ in the $800-900 \mathrm{~nm}$ range vs. solar altitude $(\alpha)$,

456 (a) Carpinus betulus (Fastigiate hornbeam; slightly different result compared to our 457 earlier work (Deng et al., 2020) due to addition of extra data collected in summer 2020); 
(b) Acer campestre (Field maple).

3.4 Correlating mean transflectance in the $800-900 \mathrm{~nm}$ range with tree crown surface albedo

The tree crown transflectance spectra sampled by in-situ spectroscopy faciliate an understanding of urban tree radiative performance in VIS (visible) and IR regions from modelling, tree crown surface albedo is commonly adopted as a constant for a species. The tree crown surface albedo represents the irradiance-weighted total transflectance over the full wavelength range, which may vary with solar time according to spatial variation of the tree crown transflectance. To examine this possibility, we linked the tree crown transflectance spectra to the tree crown surface albedo in the present study. As mean transflectance in the NIR region of $800-900 \mathrm{~nm}\left(\tau R_{\text {mean,800-900 }}\right)$ was adopted as the indicator to demonstrate the spatial distribution profile and temporal

472 variation of urban tree radiative performance in sections $3.1-3.3$, we explored the underlying mathematical relationship between the $\tau R_{\text {mean,800-900 }}$ and the tree crown surface albedo. We note that in remote sensing, the tree crown surface albedo could be estimated in a similar manner by linking to the transflectance detected at the top of tree crowns. To answer the question, we sampled three tree species, Carpinus betulus, Acer 
479

480

481

482

483

484

485

486

487

488

489

490

491

492

493

494

495

496

497

campestre, and Taxus baccata to measure the tree crown transflectance spectra in the wavelength range of 350-1000 $\mathrm{nm}$ using a miniature spectrometer with a horizontal view $\left(\mathrm{VA}=0^{\circ}\right.$ ); we simultaneously recorded the incoming and outgoing shortwave radiation towards tree crowns at the same locations using a net radiometer with the same view angle. The tree crown surface albedo was calculated as the ratio of outgoing shortwave radiation to incoming shortwave radiation, as given in Equation (3). A scale factor of the $\tau R_{\text {mean,800-900 }}$ to the tree crown surface albedo $\left(\rho_{\text {albedo }}\right)$ was introduced to explore the mathematical relationship between the two properties, as defined in Equation (4). Based on a combination of in-situ spectroscopy and shortwave radiometry, Figure 11 shows the scale factor of $\tau R_{\text {mean,800-900 }}$ to $\rho_{\text {albedo }}$ with three tree species (two individual trees for each species) at different solar altitudes. It was found that the mean transflectance in $800-900 \mathrm{~nm}$ is circa 2.5 times the tree crown surface albedo for the different tree species sampled regardless of the solar altitude, suggesting that the tree crown transflectance in the NIR region is proportionally linked to the tree crown surface albedo.

$$
\rho_{\text {albedo }}=\frac{I R R_{S W, \text { outgoing }}}{I R R_{S W, \text { incoming }}}
$$

$$
S F_{\tau R, 800-900}=\frac{\tau R_{\text {mean }, 800-900}}{\rho_{\text {albedo }}}
$$




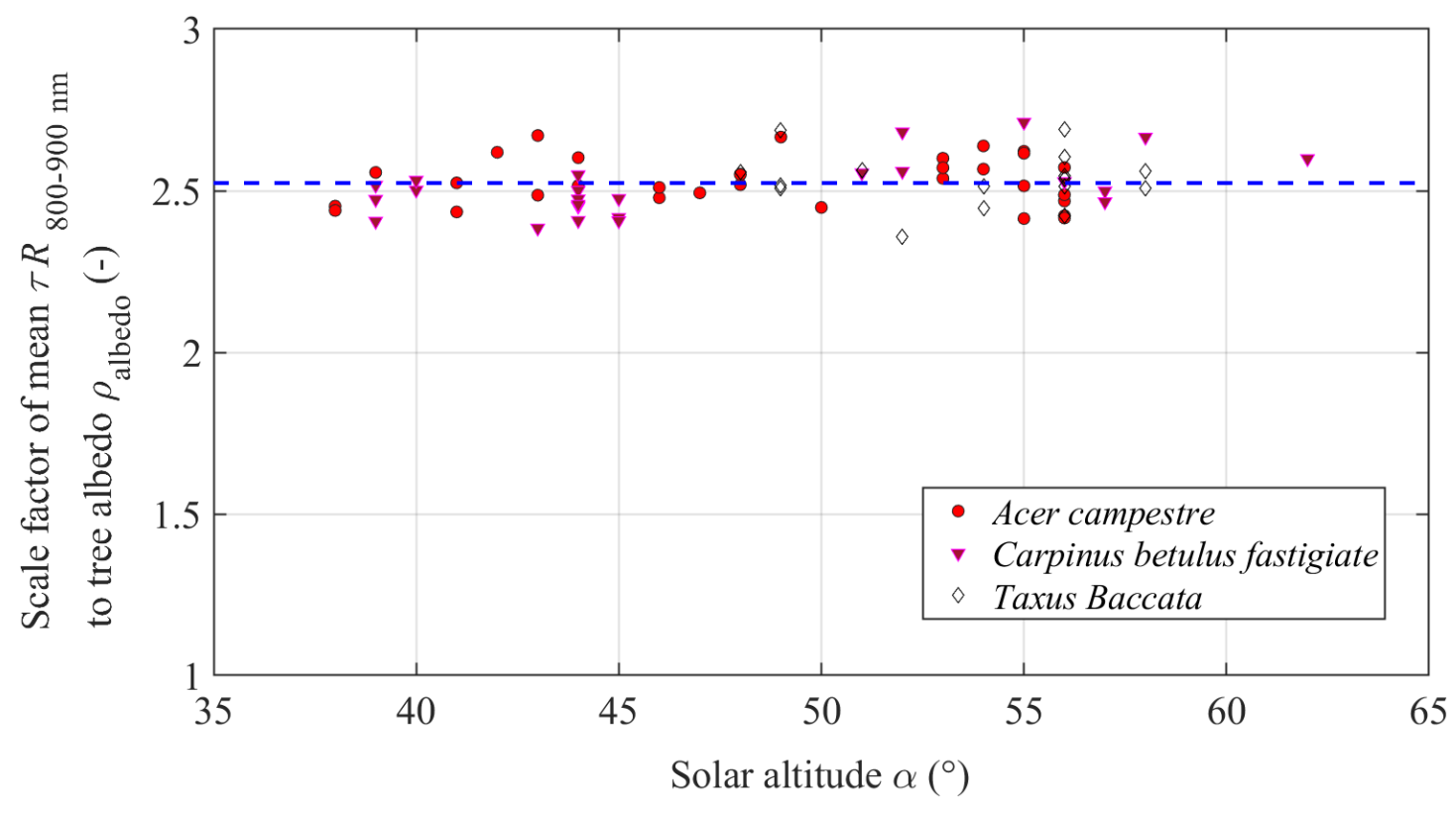

Figure 11. Scale factor $\left(S F_{\tau R, 800-900}\right)$ of mean transflectance in NIR region of $800-$ $900 \mathrm{~nm}\left(\tau R_{\text {mean,800-900 }}\right)$ to the total tree crown contour albedo $\left(\rho_{\text {albedo }}\right)$ vs. solar

501

502

503

504

505

506

507

508

509

510

511

512

altitude (average $S F_{\tau R, 800-900}$ value: 2.52 ; absolute mean deviation: $2.5 \%$; root mean square: $3.2 \%$ )

To describe the characteristics of the proportional relationship between the mean transflectance in $800-900 \mathrm{~nm}$ and the tree crown surface albedo, it was necessary to determine the proportion of IR radiation in the total transflected shortwave radiation from tree crowns in the full wavelength range.

Figure 12 shows energy decomposition of transflected shortwave radiation from the Carpinus betulus tree crown in the UV (ultroviolet), VIS (visible) and IR regions. Both the tree crown transflectance and the solar irradiance spectra in $350-1000 \mathrm{~nm}$ were sampled simutaneously by the spectrometer with a spectroradiometer mode at a point 
513

514

515

517

$3 \mathrm{~m}$ away from the tree crown in a horizontal view, meanwhile the incoming and outgoing shortwave radiation from the tree crown were recorded by the net radiometer at the same location and $30 \mathrm{~cm}$ away from the tree crown contour in view of the field of view of the net radiometer. The incoming and outgoing shortwave radiation from the tree crown were $720 \mathrm{~W} / \mathrm{m}^{2}$ and $106.6 \mathrm{~W} / \mathrm{m}^{2}$, respectively. Hence, the vertical total irradiance was $720 \mathrm{~W} / \mathrm{m}^{2}$, while the transflected shortwave radiation at the sampling point from tree crown was $106.6 \mathrm{~W} / \mathrm{m}^{2}$, resulting in a tree surface albedo of 0.148 $(=106.6 / 720)$. To simplify the energy decomposition in UV, VIS and IR regions, it was assumed that the UV radiation accounted for $7 \%$ of the total irradiance (Duffie and Beckman, 2013) and the mean transflectance in the UV region was the same as that in the $350-500 \mathrm{~nm}$ of the VIS region. The assumption in the UV region was plausible, as the proportion of UV radiation to the total solar irradiance in the full wavelength range was relatively small. In terms of energy balance in the full wavelength range for both the total irradiance and the transflected shortwave radiation from the tree crown, two Equations (5) and (6) were established with two unknown variables, e.g. solar radiation beyond $1000 \mathrm{~nm}$ up to $2500 \mathrm{~nm}\left(I R R_{\text {beyond }} 1000 \mathrm{~nm}\right)$ and the mean transflectance in the IR region beyond $1000 \mathrm{~nm}\left(\tau R_{\text {mean, beyond } 1000 \mathrm{~nm}}\right)$. In this case, the vertical total solar irradiance of $720 \mathrm{~W} / \mathrm{m}^{2}$ comprised $7.5 \mathrm{~W} / \mathrm{m}^{2}$ of UV radiation, $317 \mathrm{~W} / \mathrm{m}^{2}$ of VIS radiation, $172.7 \mathrm{~W} / \mathrm{m}^{2}$ of NIR radiation, and $179.8 \mathrm{~W} / \mathrm{m}^{2}$ in the IR region beyond 1000 $\mathrm{nm}$. Accordingly, the irradiance-weighted mean transflectance in different regions were $1.41 \%, 2.36 \%, 31.7 \%$ and $24.3 \%$, respectively, in the UV, VIS, NIR, and IR beyond 
534

535

536

537

538

539

540

541

542

543 544

545

546

547

548

549

550

$1000 \mathrm{~nm}$ regions. It was found that the transflected shortwave radiation in the IR region $(700-2500 \mathrm{~nm})$ accounted for $92.3 \%$ of the total transflected energy in the full wavelength range $(300-2500 \mathrm{~nm})$ in the measurement at a solar altitude of $45^{\circ}$. For solar altitude in the range of $37^{\circ}-58^{\circ}$ that we had sampled, it was observed that the transflected shortwave radiation in the IR region accounted for more than $90 \%$ of the total transflected energy from the tree crowns in the full wavelength range, meaning that UV and VIS radiation only accounted for a very small proportion of the total transflected energy. The feature of transflected shortwave radiation from the tree crown being dominated by IR radiation explained why the mean transflectance in the NIR region of $800-900 \mathrm{~nm}$ was directly proportional to the tree crown surface albedo.

$$
I R R_{S W, \text { incoming }}=I R R_{U V}+I R R_{V I S, 350-700}+I R R_{N I R, 700-1000 \mathrm{~nm}}+
$$

$I R R_{I R, \text { beyond } 1000 \mathrm{~nm}}$

$$
\begin{gathered}
I R R_{S W, \text { outgoing }}=\tau R_{\text {mean,UV }} \cdot I R R_{U V}+\tau R_{\text {mean,350-700nm }} \cdot I R R_{V I S, 350-700 \mathrm{~nm}}+ \\
\tau R_{\text {mean,700-1000nm }} \cdot I R R_{N I R, 700-1000 \mathrm{~nm}}+\tau R_{\text {mean, beyond } 1000 \mathrm{~nm}} \cdot I R R_{\text {beyond } 1000 \mathrm{~nm}}
\end{gathered}
$$




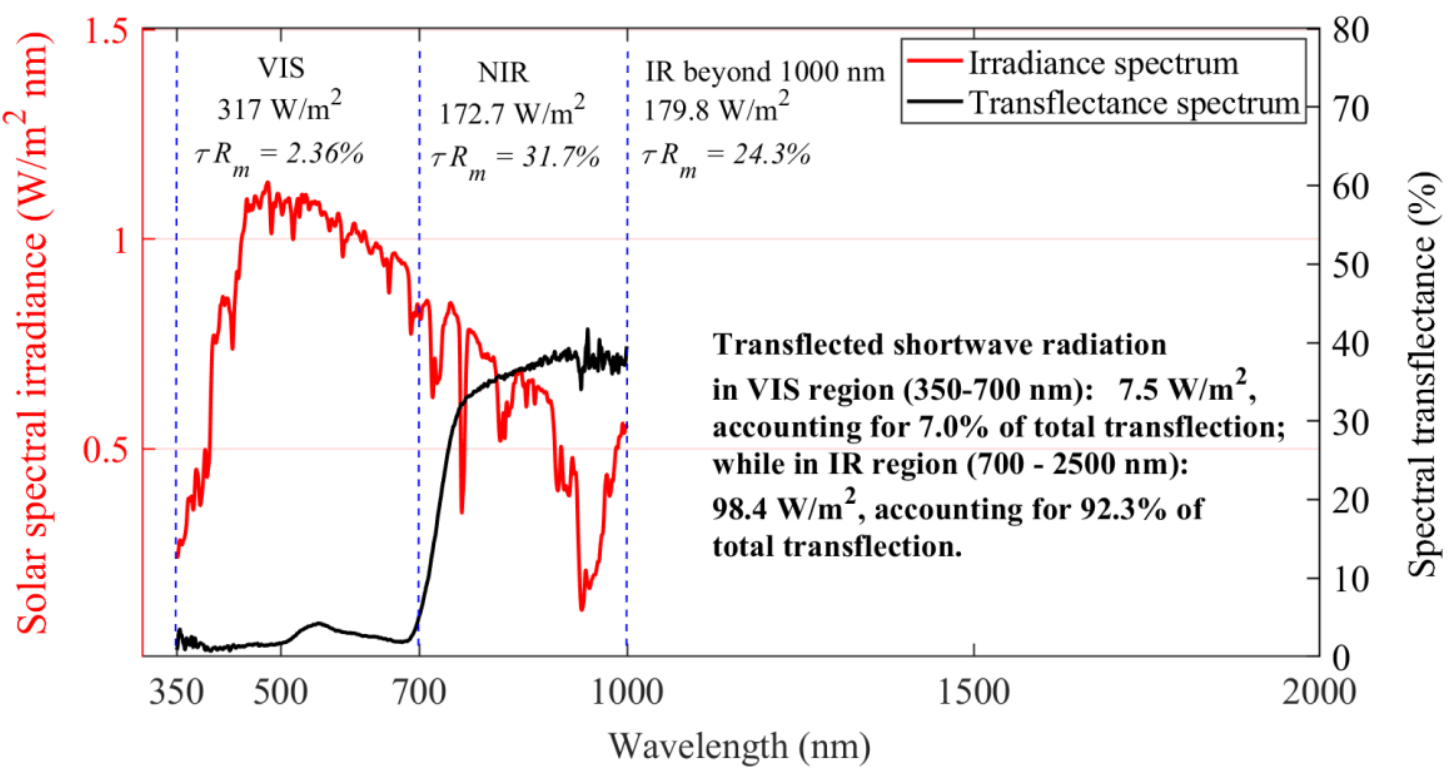

Figure 12. Energy decomposition of transflected shortwave radiation from the

Carpinus betulus tree crown in UV, VIS, IR regions (tested on 31/07/2020 at 10:33:00,

Reading, UK, Solar altitude $\alpha=45^{\circ}$; Vertical total irradiance: $720 \mathrm{~W} / \mathrm{m}^{2}$; Transflected radiation at the sampling point from tree crown: $106.6 \mathrm{~W} / \mathrm{m}^{2} ; \rho_{\text {albedo }}: 0.148$ )

3.5 Tree crown surface albedo of different species based on the tree crown

After finding in the previous section 3.4 that the mean transflectance in $800-900 \mathrm{~nm}$ ( $\tau R_{\text {mean }}$ 800-900 $)$ was 2.5 times tree crown surface albedo $\left(\rho_{\text {albedo }}\right)$ for the three different tree species sampled, the tree crown surface albedo for different species with similar properties was estimated based on tree crown transflectance spectra measurements. Combining the robust linear regression of the $\tau R_{\text {mean, 800-900 versus }}$ solar altitude for Carpinus betulus and Acer campestre in Figure 10 (a) and (b), the variation of $\rho_{\text {albedo }}$ for the two species was given in Equations (7) and (8), respectively. It is evident that the tree crown surface albedo linearly increases with solar 
567

568

569

570

571

572

573

574

575

576

577

578

579

580

581

582

583

584

585

586

587

altitude $(\alpha)$. The maximum tree crown surface albedo corresponds to maximum momentary solar altitude at solar noon.

\section{For Carpinus betulus:}

$$
\rho_{\text {albedo }}=\frac{\tau R_{\text {mean }, 800-900}}{2.5}=0.191 *(\alpha-45)+19.20 \quad(\%)
$$

For Acer campestre:

$$
\rho_{\text {albedo }}=\frac{\tau R_{\text {mean }, 800-900}}{2.5}=0.277 *(\alpha-45)+20.54 \quad(\%)
$$

Our earlier work used a wide range of in-situ tests to measure the tree crown transflectance across ten tree species commonly planted in the UK (Deng et al., 2020).

In terms of the proportional relationship between $\tau R_{\text {mean, } 800-900}$ and $\rho_{\text {albedo }}$ $\left(S F_{\tau R, 800-900}=2.5\right)$, the tree crown surface albedo for the ten tree species at typical solar altitudes of $30^{\circ}, 45^{\circ}, 60^{\circ}$ was obtained based on the statistical $\tau R_{\text {mean }, 800-900}$, as listed in Table 1. Furthermore, our earlier work revealed that interspecific differences of tree radiative performance levels in the IR region were strongly dependent on leaf size if only considering visibly dense foliage (i.e. no obvious gaps in foliage and no concave shapes, both of which are common in conifers) in the tree crown contours (Deng et al., 2020). With these caveats, the tree crown surface albedo across multiple tree species tends to be strongly dependent on leaf size. Take the moderate-size leaved species Acer campestre and Quercus robur as examples to show the difference of tree crown surface albedo at different times on a sunny day in the middle summer (June to 
589 altitude of $60^{\circ}$ (near or at noon) for Acer campestre and Quercus robur trees could be $59047.0 \%$ and $70.7 \%$ higher than that at a solar altitude of $30^{\circ}$ (in the early morning or 591 late afternoon), respectively. Adopting a constant albedo in urban microclimate 592 modelling and in the development of urban tree planning strategies, would probably 593 lead to an incorrect evaluation of the tree radiative shading effects. Hence, temporal 594 variation in tree crown surface albedo with solar time (solar altitude) is an important 595 factor to include in urban microclimate modelling. 
Table 1. Tree crown surface albedo $\left(\rho_{\text {albedo }}\right)$ at solar altitudes of $30^{\circ}, 45^{\circ}, 60^{\circ}$ based on the statistical $\tau R_{m e a n, 800-900}$ for ten tree species commonly planted in the UK

\begin{tabular}{|c|c|c|c|c|c|c|}
\hline & Solar altitude $30^{\circ}$ & & Solar altitude 45 & & Solar altitude 60 & \\
\hline Tree species & $\tau R_{\text {mean,800-900 }}(\%)$ & $\rho_{\text {albedo }}(\%)$ & $\begin{array}{l}\tau R_{\text {mean }, 800-900} \\
(\%)\end{array}$ & $\rho_{\text {albedo }}(\%)$ & $\begin{array}{l}\tau R_{\text {mean }, 800-900} \\
(\%)\end{array}$ & $\rho_{\text {albedo }}(\%)$ \\
\hline Sequoiadendron giganteum & $32.3( \pm 0.7)$ & $12.9( \pm 0.3)$ & $38.1( \pm 0.8)$ & $15.2( \pm 0.3)$ & $43.9( \pm 1.0)$ & $17.6( \pm 0.3)$ \\
\hline Carpinus betulus & $39.8( \pm 0.7)$ & $15.9( \pm 0.3)$ & $46.6( \pm 0.8)$ & $18.6( \pm 0.3)$ & $53.4( \pm 0.9)$ & $21.4( \pm 0.3)$ \\
\hline Acer campestre & $41.5( \pm 0.9)$ & $16.6( \pm 0.4)$ & $51.2( \pm 1.1)$ & $20.5( \pm 0.4)$ & $61.0( \pm 1.3)$ & $24.4( \pm 0.5)$ \\
\hline Quercus robur & $37.4( \pm 0.4)$ & $15.0( \pm 0.1)$ & $50.7( \pm 0.5)$ & $20.3( \pm 0.2)$ & $64.0( \pm 0.6)$ & $25.6( \pm 0.2)$ \\
\hline Platanus x acerifolia & $48.5( \pm 0.9)$ & $19.4( \pm 0.4)$ & $59.8( \pm 1.1)$ & $23.9( \pm 0.5)$ & $71.2( \pm 1.4)$ & $28.5( \pm 0.4)$ \\
\hline Tilia platyphyllos & $34.8( \pm 0.7)$ & $13.9( \pm 0.3)$ & $49.0( \pm 0.9)$ & $19.6( \pm 0.4)$ & $63.2( \pm 1.2)$ & $25.3( \pm 0.4)$ \\
\hline Acer $\mathrm{x}$ freemanii & $35.6( \pm 0.4)$ & $14.2( \pm 0.2)$ & $47.8( \pm 0.6)$ & $19.1( \pm 0.2)$ & $60.0( \pm 0.7)$ & $24.0( \pm 0.2)$ \\
\hline Betula pendula & $32.2( \pm 0.6)$ & $12.9( \pm 0.3)$ & $43.8( \pm 0.9)$ & $17.5( \pm 0.3)$ & $55.3( \pm 1.1)$ & $22.1( \pm 0.4)$ \\
\hline Acer platanoides & $40.6( \pm 1.3)$ & $16.2( \pm 0.5)$ & $55.1( \pm 1.5)$ & $22.0( \pm 0.6)$ & $69.5( \pm 1.9)$ & $27.8( \pm 0.7)$ \\
\hline Aesculus hippocastanum & $45.7( \pm 2.2)$ & $18.3( \pm 0.9)$ & $59.5( \pm 2.9)$ & $23.8( \pm 1.2)$ & $73.4( \pm 3.6)$ & $29.4( \pm 1.1)$ \\
\hline
\end{tabular}


598 Note: The ' \pm ' values in the brackets denote standard error of the mean. Additional data on mean transflectance in 800 - $900 \mathrm{~nm}$ was collected in summer 2020 for the species Sequoiadendron giganteum, Carpinus betulus, Acer campestre and Acer platanoides. The values of $\rho_{\text {albedo }}$ were

600 based on measurements of visibly dense foliage in tree crowns. For tree species with high incidence of crown gaps and concavities, such as

601 Sequoiadendron giganteum, correction factors should be introduced for practice use. 
Using a combination of in-situ spectroscopy and shortwave radiometry for three tree species, Carpinus betulus, Acer campestre, and Taxus baccata, spatial distribution profiles and temporal variation characteristics of the tree crown transflectance were

607 studied. The relationship between mean tree crown transflectance in the NIR region of $800-900 \mathrm{~nm}$ and tree crown surface albedo was demonstrated. The following main conclusions can be drawn:

(1) The tree crown transflectance spectra sampled at different viewing angles in the sunlit area can be normalised to an equivalent transflectance spectrum of the same magnitude level, with visibly dense foliage (without obvious gaps in foliage or concave crown contours) in the tree crowns. Tree crown transflected shortwave radiation is dominated by reflected radiation in the sunlit area. It is inferred that transflectance measurements of sampling patches in the sunlit area with different viewing angles at various heights with visibly dense foliage tend to have nearly the same normalised transflectance.

(2) It was observed that for the different tree species sampled here, the normalised spatial distribution profile of tree crown transflectance in the vertical loop around the tree crown, in concert with the solar azimuth direction, was best described as a 'mushroom chart' tilted at an angle of the momentary solar altitude. Note that in the normalised spatial distribution profile, only the 
transflectance spectra in the sunlit area were normalised, while the transflectance spectra in the shade area and transitional regions were kept with a vertical reference spectrum.

(3) Mean tree crown transflectance in the NIR region of $800-900 \mathrm{~nm}$ was 2.5 times tree crown surface albedo for each of the tree species sampled, suggesting that tree crown transflectance in the NIR region was proportionally linked to tree crown surface albedo. It was observed that the transflected shortwave radiation in the IR region accounted for more than $90 \%$ of the total transflected radiation energy from tree crowns in the full wavelength range.

(4) Tree crown surface albedo varies with solar time and linearly increases with solar altitude for all measured species. The tree crown surface albedo at solar altitudes of $30^{\circ}, 45^{\circ}$, and $60^{\circ}$ for ten tree species commonly planted in the UK was obtained, based on the proportional relationship between $\tau R_{\text {mean,800-900 }}$ and $\rho_{\text {albedo }}$, as well as tree crown transflectance measurements. The tree crown surface albedo across multiple tree species tends to be strongly dependent on leaf size if considering tree crown contours with visibly dense foliage. Using the moderate-size leaved species Acer campestre and Quercus robur as examples to show the temporal variation of tree crown surface albedo at different times of the day (based on a sunny day in the middle of summer; June to the middle of July in the UK), we found that tree crown surface albedo at a solar altitude of $60^{\circ}$ (near or at noon) for Acer campestre and Quercus robur 
trees could be $47.0 \%$ and $70.7 \%$ higher than that at a solar altitude of $30^{\circ}$ (in the early morning or late afternoon), respectively. Hence, adopting a constant tree surface albedo that neglects to account for temporal variation will likely lead to large errors in evaluation of the tree radiative shading effects when modelling the impact of trees on urban microclimates and/or developing urban tree planning strategies.

The present study has provided important insights into the crown-level radiative performance of individual isolated urban trees from multiple species. We note that future work focused on urban trees planted at different densities (e.g, in urban forestry) and in different configurations (e.g. rows, groups) will be a logical next step.

\section{Appendix A. Supplementary data}

Supplementary data for Figure 10 is uploaded in the online version.

\section{Author contribution statements}

Jie Deng: Conceptualization, Methodology, Test plan design, Experiment implementation, Data handling, Writing - Original Draft \& Editing

Brian J. Pickles: Methodology, Test plan design, Test result assessment, Writing Review \& Editing, Funding Acquisition

Li Shao: Conceptualization, Methodology, Test plan design, Test result assessment, 
665

666

667

668

669

670

671

672

673

674

675

676

677

678

679

680

681

682

683

684

685

Writing - Review, Funding Acquisition

\section{Declaration of interest}

The authors declare that they have no known competing financial interests or personal relationships that could have appeared to influence the work reported in this paper.

\section{Acknowledgment}

This work was funded by the UKRI EPSRC and NERC as part of the project 'InfruTreeCity: Understanding Infrared radiative performance of urban trees for better future city' (Grant No: EP/P023819/1). The authors wish to thank Dr. Stefan T. Smith and Dr. Christos H. Halios for constructive comments on the methodology.

\section{References}

Aminipouri, M., Rayner, D., Lindberg, F., Thorsson, S., Knudby, A.J., Zickfeld, K., Middel, A., Krayenhoff, E.S., 2019. Urban tree planting to maintain outdoor thermal comfort under climate change: The case of Vancouver's local climate zones. Build. Environ. 158, 226-236. https://doi.org/10.1016/j.buildenv.2019.05.022

Armson, D., Rahman, M.A., Ennos, A.R., 2013. A comparison of the shading effectiveness of five different street tree species in Manchester, UK. Arboric. 
687

Benham, S.E., Houston Durrant, T., Caudullo, G., de Rigo, D., 2016. Taxus baccata in Europe: distribution, habitat, usage and threats. Eur. Atlas For. Tree Species 183.

Bowler, D.E., Buyung-Ali, L., Knight, T.M., Pullin, A.S., 2010. Urban greening to cool towns and cities: A systematic review of the empirical evidence. Landsc. Urban Plan. 97, 147-155. https://doi.org/10.1016/j.landurbplan.2010.05.006

Christidis, N., Jones, G.S., Stott, P.A., 2015. Dramatically increasing chance of extremely hot summers since the 2003 European heatwave. Nat. Clim. Chang. 5, 46-50. https://doi.org/10.1038/nclimate2468

de Abreu-Harbich, L.V., Labaki, L.C., Matzarakis, A., 2015. Effect of tree planting design and tree species on human thermal comfort in the tropics. Landsc. Urban Plan. 138, 99-109. https://doi.org/10.1016/j.landurbplan.2015.02.008

Deng, J., Pickles, B.J., Kavakopoulos, A., Blanusa, T., Halios, C.H., Smith, S.T., Shao, L., 2019. Concept and methodology of characterising infrared radiative performance of urban trees using tree crown spectroscopy. Build. Environ. 157, 380-390. https://doi.org/10.1016/j.buildenv.2019.04.056

Deng, J., Pickles, B.J., Smith, S.T., Shao, L., 2020. Infrared radiative performance of urban trees: spatial distribution and interspecific comparison among ten species in the UK by in-situ spectroscopy. Build. Environ. 172, 106682. https://doi.org/10.1016/j.buildenv.2020.106682

Duffie, J.A., Beckman, W.A., 2013. Solar Engineering of Thermal Processes: Fourth 

Edition, Solar Engineering of Thermal Processes: Fourth Edition. https://doi.org/10.1002/9781118671603

Eckmann, T., Morach, A., Hamilton, M., Walker, J., Simpson, L., Lower, S., McNamee, A., Haripriyan, A., Castillo, D., Grandy, S., Kessi, A., 2018. Measuring and modeling microclimate impacts of Sequoiadendron giganteum. Sustain. Cities Soc. 38, 509-525. https://doi.org/10.1016/j.scs.2017.12.028

Garcia-Herrera, R., Díaz, J., Trigo, R.M., Luterbacher, J., Fischer, E.M., 2010. A review of the european summer heat wave of 2003. Crit. Rev. Environ. Sci. Technol. 40, 267-306. https://doi.org/10.1080/10643380802238137

Gasparrini, A., Armstrong, B., 2011. The impact of heat waves on mortality. Epidemiology. https://doi.org/10.1097/EDE.0b013e3181fdcd99

Georgi, N.J., Zafiriadis, K., 2006. The impact of park trees on microclimate in urban areas. Urban Ecosyst. 9, 195-209. https://doi.org/10.1007/s11252-006-8590-9

Gillner, S., Vogt, J., Tharang, A., Dettmann, S., Roloff, A., 2015. Role of street trees in mitigating effects of heat and drought at highly sealed urban sites. Landsc. Urban Plan. 143, 33-42. https://doi.org/10.1016/j.landurbplan.2015.06.005

Guo, Y., Gasparrini, A., Armstrong, B.G., Tawatsupa, B., Tobias, A., Lavigne, E., De Sousa Zanotti Stagliorio Coelho, M., Pan, X., Kim, H., Hashizume, M., Honda, Y., Leon Guo, Y.L., Wu, C.F., Zanobetti, A., Schwartz, J.D., Bell, M.L., Scortichini, M., Michelozzi, P., Punnasiri, K., Li, S., Tian, L., Garcia, S.D.O., Seposo, X., Overcenco, A., Zeka, A., Goodman, P., Dang, T.N., Van Dung, D., Mayvaneh, F., 
Saldiva, P.H.N., Williams, G., Tong, S., 2017. Heat wave and mortality: A multicountry, multicommunity study. Environ. Health Perspect. 125, 1-11. https://doi.org/10.1289/EHP1026

Hsieh, C.M., Li, J.J., Zhang, L., Schwegler, B., 2018. Effects of tree shading and transpiration on building cooling energy use. Energy Build. 159, 382-397. https://doi.org/10.1016/j.enbuild.2017.10.045

IPCC, 2014. Climate Change 2014: Synthesis Report. Contribution of Working Groups I, II and III to the Fifth Assessment Report of the Intergovernmental Panel on Climate Change, Ipcc.

Irmak, M.A., Yilmaz, S., Mutlu, E., Yilmaz, H., 2018. Assessment of the effects of different tree species on urban microclimate. Environ. Sci. Pollut. Res. 25, 1580215822. https://doi.org/10.1007/s11356-018-1697-8

Jamei, E., Rajagopalan, P., Seyedmahmoudian, M., Jamei, Y., 2016. Review on the impact of urban geometry and pedestrian level greening on outdoor thermal comfort. Renew. Sustain. Energy Rev. 54, 1002-1017. https://doi.org/10.1016/j.rser.2015.10.104

Kong, F., Sun, C., Liu, F., Yin, H., Jiang, F., Pu, Y., Cavan, G., Skelhorn, C., Middel, A., Dronova, I., 2016. Energy saving potential of fragmented green spaces due to their temperature regulating ecosystem services in the summer. Appl. Energy 183, 1428-1440. https://doi.org/10.1016/j.apenergy.2016.09.070

Kong, L., Lau, K.K.L., Yuan, C., Chen, Y., Xu, Y., Ren, C., Ng, E., 2017. Regulation of 
outdoor thermal comfort by trees in Hong Kong. Sustain. Cities Soc. 31, 12-25. https://doi.org/10.1016/j.scs.2017.01.018

Konijnendijk, C.C., Nilsson, K., Randrup, T.B., Schipperijn, J., 2005. Urban forests and trees: A reference book, Springer-Verlag Berlin Heidelberg. Springer-Verlag Berlin Heidelberg, New York. https://doi.org/10.1007/3-540-27684-X

Krayenhoff, E.S., Christen, A., Martilli, A., Oke, R.T., 2014. A Multi-layer Radiation Model for Urban Neighbourhoods with Trees. Boundary-Layer Meteorol. 151, 139-178. https://doi.org/10.1007/s10546-013-9883-1

Lee, H., Mayer, H., Chen, L., 2016. Contribution of trees and grasslands to the mitigation of human heat stress in a residential district of Freiburg, Southwest Germany. Landsc. Urban Plan. 148, 37-50. https://doi.org/10.1016/j.landurbplan.2015.12.004

Leuzinger, S., Vogt, R., Körner, C., 2010. Tree surface temperature in an urban environment. Agric. For. Meteorol. 150, 56-62. https://doi.org/10.1016/j.agrformet.2009.08.006

Liu, Y., Harris, D.J., 2008. Effects of shelterbelt trees on reducing heating-energy consumption of office buildings in Scotland. Appl. Energy 85, 115-127. https://doi.org/10.1016/j.apenergy.2007.06.008

Morakinyo, T.E., Lau, K.K.L., Ren, C., Ng, E., 2018. Performance of Hong Kong's common trees species for outdoor temperature regulation, thermal comfort and $\begin{array}{llll}\text { energy } & \text { saving. } & \text { Build. } & \text { Environ. 137-170. }\end{array}$ 
771

772

773

774

775

776

777

778

779

780

781

782

783

784

785

786

787

788

789

790

Moss, J.L., Doick, K.J., Smith, S., Shahrestani, M., 2019. Influence of evaporative cooling by urban forests on cooling demand in cities. Urban For. Urban Green. 37, 65-73. https://doi.org/10.1016/j.ufug.2018.07.023

Park, C.Y., Lee, D.K., Krayenhoff, E.S., Heo, H.K., Hyun, J.H., Oh, K., Park, T.Y., 2019. Variations in pedestrian mean radiant temperature based on the spacing and size of street trees. Sustain. Cities Soc. 48, 1-9. https://doi.org/10.1016/j.scs.2019.101521

Rahman, M.A., Armson, D., Ennos, A.R., 2015. A comparison of the growth and cooling effectiveness of five commonly planted urban tree species. Urban Ecosyst. 18, 371-389. https://doi.org/10.1007/s11252-014-0407-7

Rahman, M.A., Hartmann, C., Moser-Reischl, A., von Strachwitz, M.F., Paeth, H., Pretzsch, H., Pauleit, S., Rötzer, T., 2020a. Tree cooling effects and human thermal comfort under contrasting species and sites. Agric. For. Meteorol. 287, 107947. https://doi.org/10.1016/j.agrformet.2020.107947

Rahman, M.A., Stratopoulos, L.M.F., Moser-Reischl, A., Zölch, T., Häberle, K.H., Rötzer, T., Pretzsch, H., Pauleit, S., 2020b. Traits of trees for cooling urban heat islands:

A meta-analysis.

Build.

Environ.

170. https://doi.org/10.1016/j.buildenv.2019.106606

Roy, S., Byrne, J., Pickering, C., 2012. A systematic quantitative review of urban tree benefits, costs, and assessment methods across cities in different climatic zones. 
792

793

794

795

796

797

798

799

800

801

802

803

804

805

806

807

808

809

810

811

Sikkema, R., Caudullo, G., de Rigo, D., 2016. Carpinus betulus. Eur. Atlas For. Tree Species. $74-75$.

Speak, A., Montagnani, L., Wellstein, C., Zerbe, S., 2020. The influence of tree traits on urban ground surface shade cooling. Landsc. Urban Plan. 197, 103748. https://doi.org/10.1016/j.landurbplan.2020.103748

Taleghani, M., 2018. Outdoor thermal comfort by different heat mitigation strategiesA review. Renew. Sustain. Energy Rev. 81, 2011-2018. https://doi.org/10.1016/j.rser.2017.06.010

Tan, P.Y., Wong, N.H., Tan, C.L., Jusuf, S.K., Schmiele, K., Chiam, Z.Q., 2020. Transpiration and cooling potential of tropical urban trees from different native habitats.

Sci.

Total

Environ.

705 , 135764. https://doi.org/10.1016/j.scitotenv.2019.135764

Tan, Z., Lau, K.K.L., Ng, E., 2017. Planning strategies for roadside tree planting and outdoor comfort enhancement in subtropical high-density urban areas. Build. Environ. 120, 93-109. https://doi.org/10.1016/j.buildenv.2017.05.017

Tan, Z., Lau, K.K.L., Ng, E., 2016. Urban tree design approaches for mitigating daytime urban heat island effects in a high-density urban environment. Energy Build. 114, 265-274. https://doi.org/10.1016/j.enbuild.2015.06.031

Tang, M., Zheng, X., 2019. Experimental study of the thermal performance of an extensive green roof on sunny summer days. Appl. Energy 242, 1010-1021. 
813 Upreti, R., Wang, Z.H., Yang, J., 2017. Radiative shading effect of urban trees on 814 cooling the regional built environment. Urban For. Urban Green. 26, 18-24. 

different spatial arrangements of buildings and trees on microclimate. Sustain. Cities Soc. https://doi.org/10.1016/j.scs.2019.101711

Yang, A.S., Juan, Y.H., Wen, C.Y., Chang, C.J., 2017. Numerical simulation of cooling effect of vegetation enhancement in a subtropical urban park. Appl. Energy 192, 178-200. https://doi.org/10.1016/j.apenergy.2017.01.079

Zecchin, B., Caudullo, G., Rigo, D. de, 2016. Acer campestre : acero campestre. Eur. Atlas For. Tree Species 52-53.

Zhang, L., Zhan, Q., Lan, Y., 2018. Effects of the tree distribution and species on outdoor environment conditions in a hot summer and cold winter zone: A case study in Wuhan residential quarters. Build. Environ. 130, 27-39. https://doi.org/10.1016/j.buildenv.2017.12.014

Zhao, Q., Sailor, D.J., Wentz, E.A., 2018. Impact of tree locations and arrangements on outdoor microclimates and human thermal comfort in an urban residential environment. Urban For. Urban Green. 32, 81-91. https://doi.org/10.1016/j.ufug.2018.03.022

Zheng, S., Guldmann, J.M., Liu, Z., Zhao, L., 2018. Influence of trees on the outdoor thermal environment in subtropical areas: An experimental study in Guangzhou, China. Sustain. Cities Soc. 42, 482-497. https://doi.org/10.1016/j.scs.2018.07.025

Zhou, W., Wang, J., Cadenasso, M.L., 2017. Effects of the spatial configuration of trees on urban heat mitigation: A comparative study. Remote Sens. Environ. 195, 1-12. https://doi.org/10.1016/j.rse.2017.03.043 